\title{
Caracterización y tendencias tróficas de cinco lagos costeros de Chile Central
}

\author{
Oscar Parra, Claudio Valdovinos, Roberto Urrutia, Marcos Cisternas, \\ Evelyn Habit y María Mardones
}

Unidad de Sistemas Acuáticos, Centro de Ciencias Ambientales EULA-Chile, Universidad de Concepción. Casilla 160-C, Concepción, Chile. E-mail: oparra@udec.cl

\section{RESUMEN}

El presente trabajo corresponde a una caracterización geográfica y limnológica de un sistema de 5 lagos costeros, localizados en la fachada occidental de la Cordillera de Nahuelbuta (VIII Región Chile), denominados "Lagos Nahuelbutanos" (Laguna Grande de San Pedro, Laguna Chica de San Pedro, Laguna Quiñenco, Lago Lanalhue y Lago Lleulleu). Estos exhiben diversos niveles de intervención humana, debido principalmente al uso turístico y recreativo, a la infuencia urbana y al intenso uso forestal de sus cuencas hidrográficas. Los estudios realizados comprenden la geomorfología y origen de los lagos, usos históricos y actuales del suelo, caracterización y evolución de la cubierta vegetal, morfometría y batimetría, características sedimentológicas y paleolimnológicas, calidad del agua y biota acuática (fitoplancton, bentos y fauna íctica), así como algunos aspectos asociado al metabolismo de la columna de agua. Se realizó un análisis limnológico y ambiental comparativo en relación con la condición trófica actual de estos sistemas. Los resultados indican diferencias en los niveles de trofía, siendo el Lago LleuLleu el más oligotrófico y Laguna Grande de San Pedro el mas eutrófico. En general el grado de trofía y de calidad del agua de estos cuerpos de agua se relacionan con indicadores biológicos y con el nivel de intervención a que han sido sometidas sus cuencas de drenaje.

Palabras clave: cuencas hidrográficas, uso del suelo, paleolimnología, calidad del agua, biota, eutrofización, intervención antrópica.

\begin{abstract}
The present work correspond to a geographical and limnological characterization dealing with a coastal five-lake system located at the eastern piedmont of the Nahuelbuta mountain range (VIII Region, Chile) named "Lagos Nabuelbutanos" (Laguna Grande de San Pedro, Laguna Chica de San Pedro, Laguna Quillenco, Lago Lanalhue y Lago Lleulleu). The lakes show several levels of human intervention, mainly due to tourist and recreational uses, urban influence, and forestal intensive use in their hydrographic basins. The performed studies comprise the geomorphology and origin of the lakes, historical and current soil use, characterization and evolution of the plant coverage, morphometry and bathymetry, sedimentological and paleolimnological characteristics, water quality and aquatic biota (i.e., phytoplankton, benthos, and ichthyic fauna, as well as some topics associated with the water column metabolism. A comparative environmental and limnological analysis was performed, in relation to the current trophic conditions of these systems. The results show differences in trophic state, being Lago Lleulleu the most oligotrophic, and Laguna Grande de San Pedro the most eutrophic. In general, the trophic degree and water quality of these water bodies are related with biological indicators and with the level of intervention to which their drainage basins have been subjected.
\end{abstract}

Keywords: basins, soil usage, paleolimnology, water quality, biota, eutrophication, anthropic intervention.

\section{INTRODUCCIÓN}

Los lagos se originan principalmente por la obstrucción del drenaje superficial debido particularmente a procesos morfogenéticos, conformando una estructura temporal, en la historia erosional de los sistemas geográficos (Bellair \&
Pomero, 1977; Mosetti, 1977). Ellos reciben aportes sólidos y líquidos de su cuenca de drenaje, mediante escurrimiento lineal, laminar y subterráneo, razón por la cual las características de la calidad del agua y de las comunidades biológicas allí presentes, reflejan los efectos acumulados de todos los aportes de agua y materiales 
procedentes del entorno. Diversos autores destacan la estrecha relación existente entre el estado trófico de un sistema limnético y las condiciones geográficas y particularmente geomorfológicas del lago y de su cuenca de drenaje (Ryding \& Rast, 1992). Aspectos tales como la extensión, la profundidad de un lago y el aporte de material particulado, son relevantes en la determinación del ciclo de vida del sistema limnético; éstos se relacionan estrechamente con los procesos morfogenéticos de la cuenca lacustre.

La diversidad climática y geológica de Chile continental conforma una realidad territorial latitudinal, de tal magnitud, que permite la diferenciación de una gran variedad de ecosistemas terrestres y acuáticos, algunos de ellos ambientalmente relevantes. Entre estos ecosistemas acuáticos continentales relevantes se observan de norte a sur (Fig. 1), el sistema de lagos del altiplano, el sistema de lagunas hipersalinas de la segunda región, el sistema de lagos nord-patagónicos o araucanos, el sistema de lagos de la isla de Chiloé, el sistema de lagos magallánicos o patagónicos y el sistema de lagos costeros de la región centro sur denominados como "Lagos Nahuelbutanos" (Parra et al., 1999) por estar insertos en un dominio geográfico común; la vertiente litoral centronorte de la Cordillera de Nahuelbuta.

Particularmente, en la Región del Biobío, la disponibilidad de cuerpos de aguas lénticos es bastante escasa comparada con la magnitud de las aguas corrientes. En esta Región los sistemas de lagos más importantes se encuentran en la precordillera de los Andes, sobre los 800 m.s.n.m, en las zonas de nacimiento del sistema fluvial del río Biobío. Estos son el lago Laja ("Laguna de la Laja") y las lagunas Icalma y Galletué. En el sector costero de la Región, se encuentra el sistema de lagos anteriormente nombrado, los que corresponden a lagos costeros de aguas dulces, localizados en las estribaciones occidentales de la Cordillera de Nahuelbuta. El sistema de lagos "Nahuelbutanos" esta constituído por 6 cuerpos lénticos localizados en la vertiente sur occidental de la Cordillera de Nahuelbuta (parte de la Cordillera de la Costa) que se alinean de norte a sur entre los sistemas fluviales de los ríos Biobío e Imperial. Entre ellos destacan: Laguna Chica de San Pedro, Laguna Grande de San Pedro, Laguna La Posada, Laguna Quiñenco, Lago Lanalhue y Lago Lleu-Lleu.

A diferencia de los lagos que se encuentran en la parte alta y la precordillera andina de la Región, cuyas aguas tienen bajos contenidos de nutrientes, debido a una mínima intervención de sus cuencas de drenaje y ninguna influencia de asentamientos urbanos, los lagos nahuelbutanos exhiben diversos niveles de intervención humana de norte a sur. Así, los lagos nahuelbutanos septentrionales se encuentran rodeados en parte por centros urbanos, desarrollándose una importante actividad turística y recreativa en ellos. Además, la mayor parte de sus cuencas hidrográficas han sido $\mathrm{y}$ están sometidas a una intensa actividad forestal. Por otra parte, los dos lagos nahuelbutanos meridionales (Lanalhue y Lleulleu) corresponden a áreas de desarrollo indígena, lo cual constituye un componente cultural, actualmente relevante en Chile para la toma de decisiones respecto al uso de estos recursos acuáticos.

Desde esta perspectiva, los procesos que afectan la calidad y usos de estos recursos, como la eutrofización, requieren una especial atención de la comunidad científica. Es necesario generar el conocimiento de base para decidir acciones de protección ambiental que permitan su control y su uso sustentable. La eutrofización representa el proceso de envejecimiento natural de los lagos, como resultante de la acumulación gradual de nutrientes, un incremento de la productividad biológica y la depositación paulatina de sedimentos provenientes de su cuenca de drenaje. En condiciones naturales el proceso de eutrofización es lento, y las tasas de cambio ocurren normalmente a escala temporal de milenios. Sin embargo, por causas antrópicas relacionadas con el mal uso del suelo, el incremento de la erosión y por la descarga de aguas servidas domésticas, se ve acelerado a escala temporal de décadas o menos (Vollenweider, 1968).

La evaluación cuantitativa del estado trófico y el grado de contaminación de los sistemas 


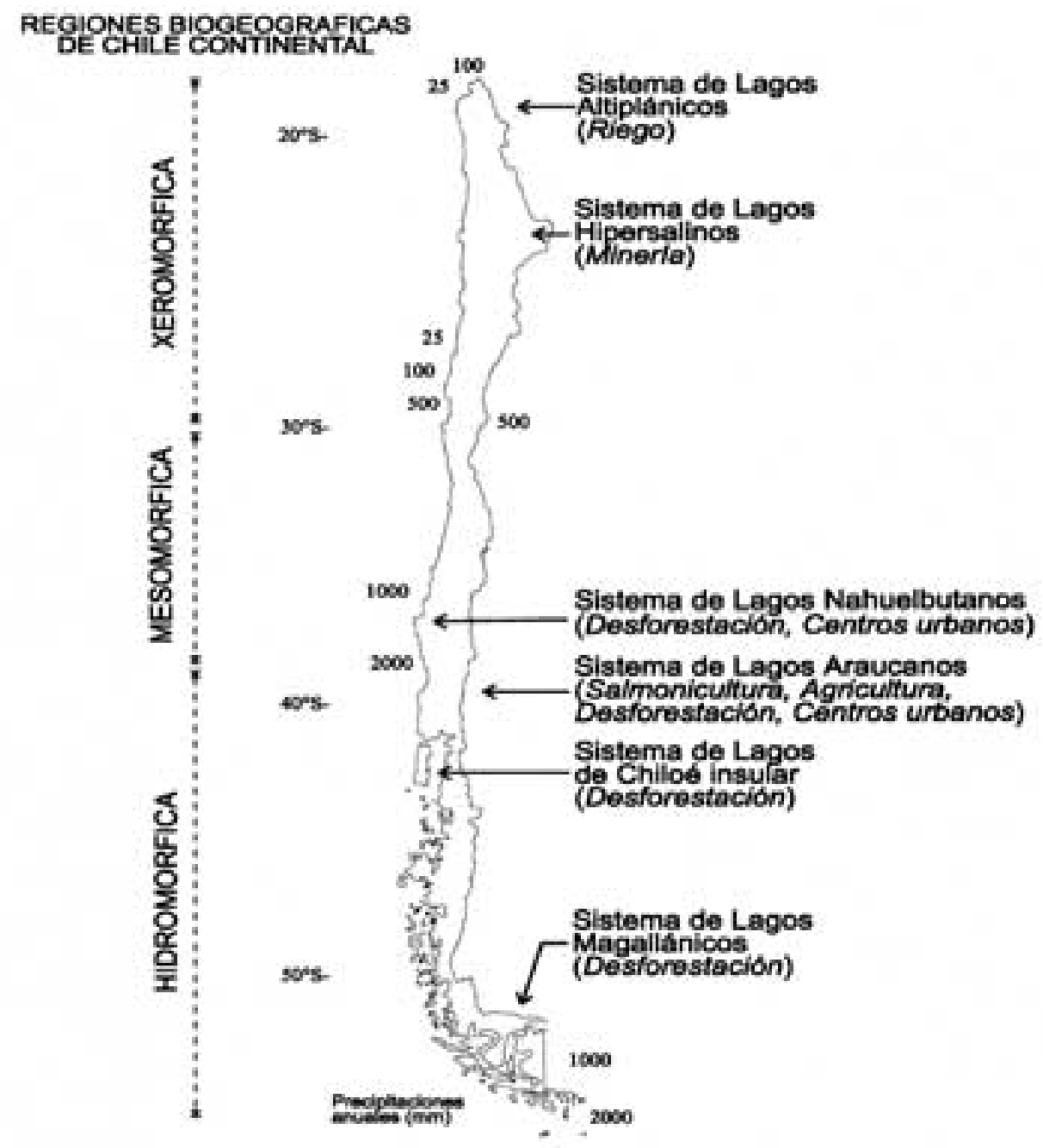

Figura 1. Localización latitudinal de los principales sistemas lacustres de Chile. Latitudinal location for the main lake systems in Chile.

lacustres, es de gran trascendencia en gestión ambiental territorial, ya que permite determinar restricciones de uso de estos recursos (e.g. abastecimiento de agua para consumo humano, baño), y orientar medidas de recuperación y mitigación cuando corresponda (e.g. colectores de aguas lluvia, forestación). Los sistemas tradicionales de evaluación del estado trófico de sistemas lacustres, se basan fundamentalmente en el contenido de fósforo y nitrógeno, y los clasifican en oligo-, meso- y eutróficos. Sin embargo, en las últimas décadas, esta aproximación ha sido motivo de discusión en la litera- tura científica (Tundisi et al., 1997), sugiriendo la utilización de un mayor número de indicadores ambientales, no solo del cuerpo de agua en sí, sino también de las relaciones con su cuenca de drenaje y con una escala temporal más amplia, que permita explicar en el tiempo las acciones y los procesos que determinaron las condiciones actuales.

Nuestro grupo de trabajo ha estudiado los cuerpos de aguas anteriormente nombrados a través de sus distintos componentes, obteniendo información básica de las características limnológicas de cada uno de ellos. Esto ha permitido 
realizar un análisis comparativo de los cinco cuerpos de agua y de sus respectivas cuencas hidrográficas, explicando en parte el estado trófico actual, sus causas, sus efectos, sus indicadores y sus tendencias.

Considerando el valor como patrimonio natural, el uso actual y potencial que representa el sistema de lagos nahuelbutanos para la segunda área mas poblada e industrializada del país, se ha decidido realizar la presente contribución, que tiene como objetivo integrar esta información y aquella todavía no publicada, realizando un análisis ambiental comparativo de las características limnológicas de los cinco cuerpos acuáticos, incluidas sus cuencas de drenaje,

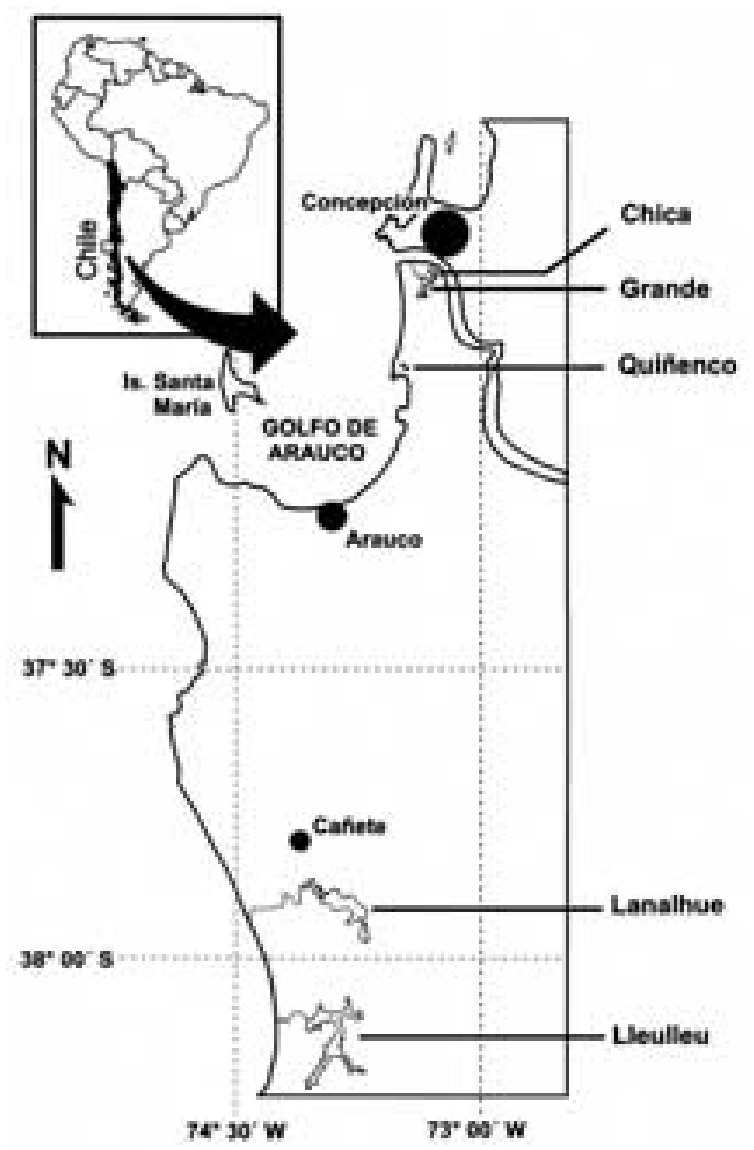

Figura 2. Localización de las lagunas Grande de San Pedro, Chica de San Pedro y Quiñenco, y de los lagos Lanalhue y Lleu-lleu. Geographic location of the lagoons Grande de San Pedro, Chica de San Pedro y Quiñenco, and the Lanalhue y Lleu-lleu lakes. poniendo especial énfasis en la condición trófica y estado de eutrofización y estimar su tendencia, para posteriormente identificar acciones de conservación y protección ambiental.

\section{ÁREA DE ESTUDIO}

Los sistemas acuáticos estudiados (Fig. 2), tienen la característica de ser cuerpos de agua cercanos a la zona litoral marina. Estos poseen similar base geológica y climatológica, donde las diferencias radican fundamentalmente en el uso de suelo, la intensidad de la actividad forestal silvícola, las actividades turísticas y la ocupación urbana de sus respectivas cuencas hidrográficas (Tabla 1).

\section{MATERIALES Y MÉTODOS}

Los estudios realizados comprendieron: geomorfología y el origen de los lagos (Mardones \& Reuther, 1999), erosión, sedimentación, usos históricos y actuales del suelo de las cuencas lacustres y la caracterización y evolución de la cubierta vegetal (Cisternas et al., 1997, 1999a, 1999b, 2000, 2001), morfometría y batimetría de los cuerpos de agua, características sedimentológicas y paleolimnología (Urrutia et al., 2000a, 2000b), calidad del agua y biota acuática (fitoplancton, bentos y fauna íctica) en cuanto a biodiversidad y como organismos indicadores, y algunos aspectos asociados al metabolismo de la columna de agua (Parra, 1989; Parra et al., 1976, 1989, 1999; Scasso \& Campos, 1998, 1999; Valdovinos \& Figueroa, 2000; Valdovinos et al., en prensa).

\section{Geología, Hidrografía, Clima y Geomorfología}

La información geológica, hidrográfica y del clima se obtuvo de los trabajos de Ferraris (1981), Ferraris \& Bonilla (1981), Fuenzalida (1971), Cier-Serplac (1976), Devynck (1970), Endlicher \& Mackel (1985), Veil (1961), Katz 
Tabla 1. Características generales de las cuencas hidrográficas y grado de intervención humana. General characteristics of the hydrographic basins and degree of human intervention.

\begin{tabular}{|c|c|c|c|c|c|}
\hline $\begin{array}{l}\text { PARAMETROS Y } \\
\text { USOS DEL SUELO }\end{array}$ & L. CHICA & L. GRANDE & L. QUIÑENCO & L. LANALHUE & L. LLEU-LLEU \\
\hline Area del lago $\left(\mathrm{km}^{2}\right)$ & 0.82 & 1.55 & 0.29 & 31.9 & 39.8 \\
\hline Area cuenca $\left(\mathrm{km}^{2}\right)$ & 4.5 & 12.7 & 3.0 & 327.43 & 538.82 \\
\hline Rel. Área cuenca / área lago & 5.5 & 8.2 & 10.3 & 10.2 & 16.8 \\
\hline Rel. Área cuenca / vol. lago & 523.3 & 992.2 & 3333.3 & 777.5 & 717.3 \\
\hline Desarrollo línea de costa & 1.8 & 2.1 & 1.5 & 2.9 & 4.2 \\
\hline$\%$ Bosque y matorral nativo & $27.13 \%$ & $5.68 \%$ & $17 \%$ & $25.2 \%$ & $14.42 \%$ \\
\hline$\%$ Plantaciones & $48.86 \%$ & $52.35 \%$ & $70.3 \%$ & $52.42 \%$ & $40.21 \%$ \\
\hline$\%$ Agricultura & $3.35 \%$ & $1.02 \%$ & $1.6 \%$ & $22.35 \%$ & $45.32 \%$ \\
\hline$\%$ Urbano & $4.9 \%$ & $4.1 \%$ & $0 \%$ & $i$ & $0 \%$ \\
\hline \%Prot.ecológica & $0 \%$ & $0 \%$ & $0 \%$ & $0 \%$ & $0 \%$ \\
\hline Evacuación aguas servidas & no & antes & no & antes & no \\
\hline $\begin{array}{l}\text { Actividad turística y } \\
\text { recreativa (camping y playas) }\end{array}$ & intensa & regular & ninguna & $0.11 \%$ & $0.05 \%$ \\
\hline Invasión de macrófitas & Sí & Sí & No & No & No \\
\hline Grado trófico & Mesotrófico & Eutrófico & Distrófico & Eutrófico & Oligotrófico \\
\hline Macrófitas acuáticas & Abundantes & Muy abundantes & Escasas & Regular & Escasas \\
\hline Estratificación de verano & Sí & No & No & Sí & Sí \\
\hline
\end{tabular}

(1970). El levantamiento geomorfológico detallado se efectuó mediante la fotointerpretación de los vuelos (1994-1995) y de un vuelo particular (1996) solicitado por los investigadores. El sistema morfogenético fue clasificado basándose en criterios morfológicos, morfométricos, sedimentológicos, litológicos y de uso del suelo, aspectos que fueron relevados, analizados $\mathrm{y}$ evaluados directamente en terreno (Mardones \& Reuther, 1999).

\section{Uso histórico del uso del suelo}

Se realizó un detallado análisis de fotointerpretación para una de las cuencas más representativas. Se utilizaron fotografías aéreas de la cuenca de Laguna Chica (vuelo Trimetrogon 1943, vuelo Hycon 1955, vuelo OEA 1961, vuelo SAF, 1981, vuelo SAF 1994). La información se traspasó, corrigiendo digitalmente las diferentes escalas, a la cartografía base (1:10 000). Se lograron seis diferentes cartas de uso mostrando su evolución de los últimos 50 años Esta carto- grafía fue ingresada al SIG Arc/Info, separando los usos en diferentes coberturas. A través del SIG se obtuvo el Cambio Total entre periodos, es decir, se identificó, por traslape digital, las áreas que sufrieron cambios entre los años estudiados, independientemente de los tipos de uso (Cisternas et al., 2001).

\section{Cambios en las tasas de erosión y sedimentación}

Se determinaron las tasas de erosión-sedimentación de Laguna Chica, considerándola como representativa de los 5 lagos en estudio. Esta información fue posteriormente comparada con las modificaciones de uso del suelo. Mediante geocronología isotópica $\left({ }^{210} \mathrm{~Pb}\right.$ y $\left.{ }^{137} \mathrm{Cs}\right)$ y paleopalinología (Cisternas et al., 1997, Urrutia et al., 2000, Cisternas et al., 2001), se determinaron las tasas de sedimentación de un core obtenido en la parte más profunda del lago. Considerando determinadas premisas se infirieron las tasas históricas y actuales de erosión en la cuenca . 


\section{Comparación entre las condiciones prehispánicas y actuales}

Se tomaron cores en la parte más profunda de las Lagunas Grande y Chica de San Pedro y en cada caso se obtuvieron los centímetros superficiales (representando a las condiciones actuales) y los más profundos (representando a las condiciones prehispánicas). Los sedimentos inferiores fueron datados con ${ }^{14} \mathrm{C}$, para corroborar su condición prehispánica. Se analizaron las diatomeas, para determinar calidad del agua, y su polen, para reconocer la evolución de la vegetación en la cuenca. (Cisternas et al., 1999a, b; Urrutia et al., 2000, Cisternas et al., 2001).

\section{Morfometría y batimetría}

El levantamiento batimétrico se realizó utilizando un ecosonda Lowrance X-16 con $192 \mathrm{kHz}$ de frecuencia y un transductor de $8^{\circ}$ (Lowrance Electronics, INC.) con una sensibilidad de $\pm 0,1$ $\mathrm{m}$. El posicionamiento de los transectos se realizó utilizando las cartas del IGM, escala 1:50 000 y puntos notables en las orillas de los lagos. En el caso de Laguna Chica de San Pedro, Laguna Grande de San Pedro y el Lago Lanalhue se procedió a una actualización de los mapas batimétricos realizados por Dellarossa \& Parra (1985) y Scasso (1996). La determinación de los principales parámetros morfométricos se realizó siguiendo a Hutchinson (1957).

\section{Sedimentología}

La determinación de MOT se realizó de acuerdo a la metodología propuesta por Mills (1978), el análisis granulométrico y textural siguiendo Wentworth (1922).

\section{Calidad del agua}

Con el objeto de considerar la variabilidad temporal de las características físicas y químicas de los lagos, fueron muestreados estacionalmente durante los períodos de verano (enero 1997), otoño (mayo 1997), invierno (agosto 1997) y pri- mavera (diciembre 1997). Las muestras fueron obtenidas a las distintas profundidades con una botella Rüttner de $2 \mathrm{~L}$ de capacidad y transportadas al laboratorio en frascos plásticos de $5 \mathrm{~L}$ a $c a$. $4^{\circ} \mathrm{C}$, y analizadas dentro de las primeras 6 horas de obtenidas. Las muestras fueron analizadas de acuerdo a las metodologías estándar indicadas por la American Public Health Association (APHA). Las determinaciones realizadas in situ fueron las siguientes: temperatura (termómetro de mercurio), $\mathrm{pH}$ (pH-metro Shott), conductividad (conductivímetro Hanna), transparencia (disco Secchi Hydro-Bios) y turbidez (turbidímetro Milton-Roy Co.). Las determinaciones realizadas en laboratorio fueron las siguientes: oxígeno disuelto (método de Winckler), nitrógeno total (método de Kjendall), fósforo total (método molibdato-tungstato), alcalinidad (titulación con $\mathrm{HCl}$ ) y seston total (gravimetría).

\section{Fitoplancton}

En cada lago se establecieron dos o tres estaciones de muestreo, una en el sector de entrada del (o los) afluentes principales, otra en la zona de mayor profundidad y que generalmente correspondió al centro del lago y finalmente una tercera, en las proximidades del efluente principal del lago. Estos se efectuaron en verano (enero 1997), otoño (mayo 1997), invierno (agosto 1997) y primavera (diciembre 1997). Se utilizaron una red de $55 \mathrm{~mm}$ de trama y la botella muestreadora Rüttner. Se trabajó con un microscopio invertido Karl Zeiss y para el recuento se utilizó el procedimiento descrito en Utermöhl (1957). Mayor información sobre la metodología relacionada con la comunidad fitoplanctónica referirse a Parra et al., (1999). La determinación taxonómica se basó fundamentalmente en los trabajos de Parra et al., 1976, 1980, 1981,1982, 1983 y Rivera et al., 1983.

\section{Metabolismo bentónico}

Empleando un core de gravedad $(48 \mathrm{~mm}$ de diámetro interior; 0.51 de longitud), en enero de 1997 se obtuvieron muestras no perturbadas de 
sedimento en los sectores más profundos de los lagos. Las tasas de decaimiento de oxígeno fueron determinadas incubando los cores en oscuridad a temperatura constante $\left(18 \pm 0.5^{\circ} \mathrm{C}\right)$ siguiendo a (Newrkla \& Gunatilaka, 1982). Para el estudio de la dinámica de la temperatura y contenido de oxígeno sobre el fondo de los lagos, en enero, mayo, agosto y diciembre de 1997, se obtuvieron muestras de agua con una botella Rüttner a $c a .30 \mathrm{~cm}$ del fondo. $\mathrm{La}$ temperatura fue medida con un termómetro de alcohol (Hydro-Bios), y el oxígeno disuelto determinado con el método de Winckler (ver Strickland \& Parsons, 1979).

\section{Zoobentos}

Los muestreos se realizaron en los meses de agosto-septiembre de 1997. Se tomaron 8 réplicas para la parte litoral y 4 réplicas para la zona profundal. En la zona litoral se muestreó manualmente empleando cuadrantes de $0.1 \mathrm{~m}^{2}$. Las muestras de la parte profundal se obtuvieron mediante una draga Petit-ponar de $0.02 \mathrm{~m}^{2}$ de mascada. Todas las muestras se tamizaron con una trama de $500 \mu \mathrm{m}$, se fijaron con formalina al 10\%. La macrofauna se separó e identificó una lupa binocular. Para el análisis espacial de las comunidades bentónicas, se analizó una matriz de densidad (individuos por $\mathrm{m}^{2}$ por especie y estación de muestreo) empleando un análisis de conglomerados y escaleo no-métrico multidimensional (NMDS). Las estaciones (muestras) se compararon y agruparon, para definir áreas con similar composición biológica (análisis normal o tipo- $q$ ).

\section{Fauna íctica}

El análisis de las comunidades de peces se realizó sobre la base de la información aportada por Corfo (1995) para los lagos Lleulleu y Lanalhue, y Scasso (1996) y Scasso \& Campos (1998 y 1999) para lagunas Grande y Chica. No existen antecedentes sobre la ictiofauna del lago Quiñenco. El estudio de la fauna íctica de Lleulleu y Lanalhue se basó en dos muestreos realizados en invierno y verano de 1995. En ambos casos se utilizó un único arte de pesca, consistente en redes de trasmallo, por lo que no se incluyó en este estudio el muestreo de la zona litoral de los lagos. El estudio de lagunas Grande y Chica incluyó 5 muestreos en los meses de noviembre de 1993, enero, marzo, junio y septiembre de 1994. Las comunidades pelágicas se estudiaron mediante métodos hidroacústicos (ecosonda Lowrance X16) y capturas con redes monofilamento de $40 \mathrm{~m}$ de largo y $2.5 \mathrm{~m}$ de ancho y $32,35,45$ y $55 \mathrm{~mm}$ de entrenudo. La producción se estimó mediante los modelos de Downing et al., (1990) y Downing \& Plante (1993) y el máximo rendimiento sostenido mediante el método de Graham (Ricker, 1981). La comparación de estos parámetros entre ambos sistemas se efectuó utilizando ANOVA. La comunidad litoral se muestreó mediante redes de arrastre en las mismas épocas de año. Para el estudio de edades y crecimiento de Odontesthes bonariensis se utilizó el método de von Bertalanffy (1938).

\section{RESULTADOS}

\section{Geología}

Los sistemas lacustres se distribuyen de Norte a Sur en la ladera occidental de la Cordillera de Nahuelbuta, unidad morfoestructural de la Cordillera de la Costa de Chile Centro-Sur (Región del Biobío). Sus cuencas hidrográficas se abren y drenan hacia las llanuras costeras en el sector septentrional y hacia las plataformas marinas y llanuras litorales en el Sur.

Los afloramientos rocosos varían en naturaleza y en edad de $\mathrm{E}$ a $\mathrm{W}$; mientras que la vertiente cordillerana donde se emplazan las cuencas lacustres está conformada por rocas cristalinas y metamórficas, la franja más cercana al litoral, se estructura en rocas sedimentarias clásticas y sedimentos de origen marino, fluvial y eólico.

Desde el margen septentrional del lago Lanalhue hasta el río Biobío, aflora el Basa- 
mento metamórfico Serie Oriental, constituido por metagrauvacas, filitas, rocas córneas y gneises, de edad Paleozoico superior. Al Sur del lago Lanalhue y en toda la hoya del lago Llelleu, las rocas estructurantes del relieve corresponden a la Serie Occidental del Basamento metamórfico. Esta serie comprende principalmente micaesquistos y metacherts, muy deformados; profundamente meteorizados por los diferentes agentes climáticos, los que han generado suelos arcillosos de color rojizocastaño, interestratificados con depósitos de ladera (Endlicher \& Mäckel, 1985). Las rocas cristalinas intrusivas, reconocidas principalmente en el margen nororiental de la cuenca del lago Lanalhue, corresponden al Batolito de la Costa, unidad informal compuesta de granitos, tonalitas, granodioritas y dioritas, con zonas de migmatitas y gneises. Este emerge en la parte central de la Cordillera de Nahuelbuta, intruye al Basamento metamórfico y ha sido datado del Paleozoico superior (Ferraris, 1981).

En el margen $\mathrm{N}$ del área de estudio, en la zona de contacto entre la Cordillera costera y las llanuras litorales afloran rocas sedimentarias continentales eocénicas atribuidas a la Formación Cosmito (Veyl, 1961), conformada principalmente por lutitas y arcosas. Estos afloramientos se distribuyen como una franja discontinua de dirección NE-SO, alternando con las rocas metamórficas Paleozoicas, al $\mathrm{S}$ de Laguna Grande de San Pedro. Hacia el extremo Sur de dicha área estas características litológicas se mantienen, ya que se adosan al cordón montañoso terrazas esculpidas en rocas sedimentarias de edad Terciaria; las formaciones más antiguas observadas son de edad Eocénica y las más recientes, corresponden a rocas de la Formación Tubul, de edad Plioceno superior. En ambos casos, predominan rocas del tipo lutitas y areniscas (Ferraris \& Bonilla, 1981).

Las 1lanuras situadas al Oeste de las cuencas lacustres están constituidas por sedimentos marinos, fluviales y eólicos de edad Pleistocénica-Holocénica.

Desde el punto de vista tectónico, el rasgo más destacado es la foliación de la Serie meta- mórfica Occidental, la que está asociada a un proceso de metamorfismo-deformación y fallamientos en bloque, de edad Postmiocénica; deformaciones que se relacionan con el alzamiento de la Cordillera de Nahuelbuta . Las fracturas de gran ángulo (mayor de $45^{\circ}$ ), la mayoría con manteo cercano a la vertical, parecen corresponder a movimientos de tipo normal, presentando rumbos generalmente ENE, NW y NNE. Dichas fracturas, son fundamentales para comprender tanto el trazado geométrico de la red hidrográfica, como la morfología y la batimetría de las cuencas lacustres. Esta influencia es clara en la Laguna Grande de San Pedro, cuyo sistema léntico ocupa un valle de línea de falla, de dirección NNE-SSO, que discurre casi paralelo a la línea costera. También tiene incidencia en el flujo de agua subterránea que alimenta los sistemas lacustres.

\section{Clima}

Este sistema de lagos está localizado en la zona media y húmeda del área costera dentro del área de influencia Mediterránea (Fuenzalida, 1971). Según Cier-Serplac (1976) las precipitaciones incrementan de Oeste a Este debido al efecto climático de barrera que ejerce la Cordillera de Nahuelbuta. Desde el norte hacia los lagos mas al sur del sistema, las precipitaciones varían entre $1.250 \mathrm{~mm}$ a cerca de 2500 $\mathrm{mm}$. Las lluvias se concentran principalmente en invierno (Mayo-Octubre). La temperatura media anual es 12 a $13{ }^{\circ} \mathrm{C}$. Desde Mayo a Agosto la dirección de viento dominante varía entre $\mathrm{W}$ y $\mathrm{N}$ y durante el resto del año varía entre S y SW. Esta alternancia es debida a una influencia anticiclónica durante el verano, y durante la influencia ciclónica con la aproximación del frente polar que es el que genera alteraciones atmosféricas en el invierno.

\section{Geomorfología}

Los cinco lagos se emplazan en valles de la Cordillera de Nahuelbuta cuyo drenaje local ha sido bloqueado. Existen importantes diferencias 
morfométricas y morfogenéticas entre los tres lagos situados en el margen $\mathrm{N}$ del área de estudio (Lagunas Chica y Grande de San Pedro y Laguna Quiñenco) y aquellos situados en la zona meridional (lagos Lanalhue y Lleulleu).

\section{Los sistemas lacustres septentrionales}

Las cabeceras de las cuencas lacustres se emplazan en los cordones montañosos de erosión hídrica, de la naciente Cordillera de Nahuelbuta, estructurados en roca metamórfica Paleozoica; cuyos interfluvios presentan orientación $\mathrm{N}$ y ONO y altitudes $>400 \mathrm{~m}$. Adosada a la cordillera se aprecia una terraza de erosión marina de 65 a $100 \mathrm{~m}$ de altitud, $450 \mathrm{~m}$ de ancho dispuesta como una franja continua de dirección $\mathrm{N}-\mathrm{S}$ y pendiente $<5^{\circ}$, conformada tanto por roca sedimentaria Eocénica, como por filitas y esquistos Paleozoicos. El contacto con la cordillera es generalmente abrupto y lineal, lo que permitiría suponer que se trata de un escarpe adaptado a líneas de falla. Tanto los cordones como las terrazas están disectados por pequeños y estrechos valles de fuertes pendientes longitudinales.

Al Oeste y ONO de estas unidades morfológicas se sitúa la llanura litoral de San PedroCoronel, cuya altitud media es de aproximadamente 6 m.s.n.m. Conforma una franja continua de 1-4 km de ancho, de dirección N-S, modelada por cordones litorales y dunas. Por el número y grado de conservación de cordones litorales observados, se estima que la llanura se habría modelado entre el Tardiglacial y el Reciente, al menos en seis estadios de retroceso del mar. Este tipo de modelado se presenta particularmente, en el frente de los lagos Quiñenco y San Pedro Grande. En el margen Norte de las dos Lagunas de San Pedro, el río Biobío construye una terraza de acumulación constituida por sedimentos arenosos basálticos, de edad Pleistocénica-Holocénica, parcialmente modelada por dunas.

\section{Los sistemas lacustres meridionales}

En el margen Sur del área de estudio, los lagos Lanalhue y Lleulleu emplazan sus cabeceras en el eje mismo de la Cordillera de Nahuelbuta. La cordillera está modelada por cordones y restos de superficies de erosión de origen continental, estructurados en rocas metamórficas (filitas y esquistos) de edad Paleozoica, los que se elevan progresivamente hacia el E de 500 a 800 m.s.n.m., a través de bloques quebrados por un sistema de fallas ONO-ESE y ENE-OSO.

Siguiendo las mismas direcciones estructurales citadas anteriormente, los ejes de los lagos se han emplazado en antiguos valles adaptados a la estructura, tal como se aprecia por su morfología y batimetría. Del mismo modo, las cuencas hidrográficas de ambos sistemas, presentan trazados angulosos que evidencian la influencia estructural.

El contacto con la llanura litoral se produce a través de niveles decrecientes de terrazas conformadas por areniscas y lutitas Terciarias, cuyas altitudes varían entre 25 y poco más de 200 m.s.n.m. La morfología plana, su disposición en franjas paralelas a la línea costera, el afloramiento de rocas sedimentarias marinas de edad Terciaria testigos de antiguas fases de transgresión marina, permiten asumir que estos niveles de terraza adosados a la Cordillera de Nahuelbuta, son de abrasión marina. Los niveles de terraza mejor desarrollados son aquellos situados más próximos a la costa, suponiéndose por esta razón que son también los más jóvenes. Ellos se distribuyen irregularmente entre los 25-30m, 50m y 70-80m.s.n.m. El resto de las terrazas, están representadas por retazos muy fragmentados, exceptuando el nivel de 200 m.s.n.m. que presenta mayor continuidad.

El frente del lago Lleulleu está modelado por la terraza marina de $25-30 \mathrm{~m}$, sobre la cual sobreyacen dunas longitudinales, las que no están relacionadas con la obstrucción del drenaje, puesto que sobreyacen a las terrazas marinas, a un nivel superior al espejo de agua. La terraza de $50 \mathrm{~m}$ de altitud, está ampliamente representada en el frente del lago Lanalhue; sobre ella no se observan modelados de origen eólico. Esta planicie de origen marino-eólico inclinada hacia el Oeste, tiene $6 \mathrm{~km}$ de ancho en el sector Norte y se estrecha progresivamente hacia el Sur, hasta desaparecer en el sector de Quidico, donde las 
estribaciones cordilleranas caen directamente al océano formando acantilados rocosos. Se reconocen aquí una secuencia de cordones dunarios de diferentes edades y de altitudes que varían entre 16 y $47 \mathrm{~m}$. En el lago Lanalhue las dunas más próximas al cuerpo de agua, quedan distantes unos $4 \mathrm{~km}$ del frente del lago, de modo que sus riberas están modeladas en areniscas de edad Terciaria. En el frente del lago Lleulleu, la llanura litoral tiene cerca de $2.6 \mathrm{~km}$ de ancho y las dunas se aproximan al frente mismo del lago, observándose allí que los sedimentos eólicos sobreyacen una formación de rocas sedimentarias de edad probablemente Eocénica. Este modelado no tiene mayor influencia en la formación del lago, pero lo nutren de sedimentos por la deflación eólica cuando la cobertura vegetal es débil. Los lagos están drenados por los ríos Lleulleu y Puyehue-Paicaví.

El lago Lanalhue se sitúa a 12 m.s.n.m., inunda un estrecho valle de la Cordillera de Nahuelbuta de orientación SE-NO. Su morfología y batimetría tienen estrecha relación con los accidentes tectónicos que estructuran la cuenca. El lago se divide en tres secciones: la sección interior es la menos profunda $(4 \mathrm{~m}) \mathrm{y}$ de fondo plano; se dispone en dirección Norte-Sur y tiene $3 \mathrm{~km}$ de longitud y $1.5 \mathrm{~km}$ de ancho. Está parcialmente seccionada por el delta de los ríos Elicura y Calebu y se comunica con el resto del lago, a través de un estrecho (Pta. El Sapo). La parte central tiene $8 \mathrm{~km}$ de longitud y 2-3 kms de ancho; se dispone en dirección SE$\mathrm{NO}$ y su fondo tiene la forma de un estrecho canal, de laderas irregulares, cuya profundidad aumenta en dirección a la costa, de 14 a 22 m.b.n.m. El trazado de las riberas se presenta accidentado por penínsulas y ensenadas. Finalmente, el sector frontal es el más estrecho y profundo: tiene la forma de una $\mathrm{T}$ volcada hacia el Oeste, $3 \mathrm{~km}$ de largo, entre 0.5 y 0.8 $\mathrm{km}$ de ancho y 24 m.b.n.m. de profundidad. Hacia el Este, una península estructurada por rocas sedimentarias de la terraza de abrasión marina localizada en el sector de El Banquete, genera un umbral que dificulta la conexión entre las dos últimas secciones.
El lago Lleulleu tiene una forma lobulada, angulosa, cuyo trazado repite las direcciones estructurales observadas en la cordillera: NNESSO y O-E. Se ha formado por la obstrucción de dos valles principales de dirección E-O: los valles de Huillinco y Mahuilque y un eje de dirección NNE-SSO, casi paralelo a la línea costera, situado en la falla que separa la Cordillera de Nahuelbuta de las terrazas litorales. El lago tiene una altitud de 20 m.s.n.m., 0.5 a $3 \mathrm{~km}$ de ancho y el eje mayor, de dirección NNE-SSO se extiende por aproximadamente $17 \mathrm{~km}$ de longitud. En cuanto a su batimetría, la parte frontal del lago que se inserta en las terrazas litorales es la de menor profundidad $(10 \mathrm{~m})$, mientras que en los lóbulos internos se ha estimado en más de $40 \mathrm{~m}$. La compartimentalización batimétrica del sistema, al igual que en el Lanalhue se relaciona con líneas de falla que accidentan el borde cordillerano.

\section{Origen de los lagos}

Los sistemas lacustres de Lanalhue y Lleulleu, emplazados al sur del área de estudio tienen un origen distinto a aquellos situados en las cercanías de Concepción (las Lagunas Chica y Grande de San Pedro y laguna Quiñenco). La formación de los primeros, ha sido interpretada a la luz de los modelos neotectónicos para la plataforma de Arauco. Estos autores demuestran que a partir del Pleistoceno, la plataforma de Arauco habría funcionado como una zona de deformación cosísmica, tectónicamente independiente de la Cordillera de Nahuelbuta. Movimientos de emersión de la plataforma estarían asociados a la ocurrencia de grandes terremotos, con recurrencia de al menos uno por siglo. Se estiman movimientos de solevantamiento de las terrazas costeras de $0.25 \mathrm{~m} / \mathrm{siglo}$ en la parte frontal de los lagos. Esto permite sugerir que dichos lagos corresponden a valles costeros, cuyo drenaje habría sido obstruido en el Pleistoceno reciente, por las formaciones rocosas de la plataforma de Arauco debido a las periódicas crisis sísmicas.

Los lagos litorales Lagunas Chica y Grande de San Pedro y Laguna Quiñenco, se emplazan 
en antiguos valles de la Cordillera de la Costa cuyo drenaje ha sido bloqueado por dunas y cordones litorales. Tres factores se combinan para explicar su formación: el importante aporte de arenas basálticas a la costa provocado por descargas lacustres en el alto valle del Laja (Mardones \& Jaque, 1996), las transgresiones y regresiones marinas de origen glacioeustático y la neotectónica co-sísmica Cuaternaria, que en este sector ha actuado con menor intensidad y distintamente en los bloques y fosas que estructuran la llanura de Concepción y Coronel.

En relación a Las lagunas de San Pedro, a juzgar por la batimetría y la potencia de los depósitos de arena en su frente, es posible que éstas se hayan formado y destruido subsecuentemente desde fines del Riss al Actual, debido a las variaciones glacioeustáticas del nivel marino en el Pleistoceno superior. De hecho, la última transgresión marina ocurrió entre el $8000 \mathrm{BP}$ y el $6400 \mathrm{BP}$; ésta aumentó en $5 \mathrm{~m}$ el nivel actual del mar el que habría inundado al menos parcialmente éstos valles, formando lagunas. A partir de este momento, viene una fase de regresión marina posiblemente asociada a solevantamientos co-sísmicos, lo que permite la formación sucesiva de crestas de playa y cordones dunarios, que finalmente construyen los sistemas lacustres actuales, desconectados del mar. En cuanto a la laguna Quiñenco, ésta ha sido originada en un periodo previo a la llegada de la última formación de arenas negras, ya que el cordón litoral que la cierra está construido por arenas cuarcíferas. Si se considera la propuesta morfogenética de Mardones \& Jaque (1996), su formación sería previa al periodo Tardiglaciar (>15000 BP) y relacionada estrictamente con la transgresión flandriana y los solevantamientos costeros posteriores a este evento.

\section{Hidrografía}

Las hoyas hidrográficas de estos cinco lagos están conformadas por pequeñas cuencas costeras exorreicas, que drenan la vertiente occidental de la Cordillera de Nahuelbuta y tienen como nivel de base los sistemas lénticos. La jerarquía de estas cuencas va desde drenes de orden 6 en las cuencas más grandes observadas en el Lago Lleulleu (ríos Huillinco y Mahuilque) hasta orden 1 en las cuencas más pequeñas. En las lagunas de San Pedro las cuencas de mayor jerarquía son de orden 3 . La red de drenaje se caracteriza por distintos patrones y densidades de canales, debido al control geológico y estructural del área. Sobre el Basamento cristalino, el patrón de drenaje es dendrítico con densidad media. En las terrazas de abrasión marina, en cambio, se observa un patrón de drenaje paralelo, con orientación principal de NNE a SSW o SSE-NNW. Según Ferraris y Bonilla (1981), esto se debe a una adaptación de los cursos fluviales a los lineamientos estructurales. Aquí la densidad de drenaje es gruesa, debido a la alta permeabilidad de estas rocas, lo que además permite el desarrollo de valles profundos.

\section{Vegetación y uso del suelo}

La vegetación original del área de localización del sistema lacustre se inserta en la transición entre las regiones meso e hidromórfica (Di Castri, 1968). El bosque esclerófilo se contacta con el del roble-laurel-lingue (Nothofagus spp. Crptocarya alba, Persea lingue), que se desarrolla más al Sur. En las partes altas de las cuencas todavía existen especies de Nothofagus, $N$. oblicua ("Roble") y N. procera ("Raulí"). Este bosque al ser talado origina matorrales esclerófilos, los cuales a su vez al ser explotados, se convierten en comunidades arbustivas bajas. Estos hábitats son rápidamente colonizados por malezas introducidas, como la "retamilla" (Telline monspessulana), las que forman comunidades asociadas a renovales del antiguo bosque esclerófilo. Sobre esta situación vegetacional y edáfica se ha desarrollado el proceso de reforestación con especies exóticas, Pinus radiata y Eucalyptus spp., el primero en mucho mayor porcentaje (cerca del $80 \%$ de la actual cubierta vegetacional). En las quebradas mas profundas de las cuencas del sistema se observan restos de vegetación nativa como especies de "Olivillo" (Aextoxicum punctatum), "Peumo" 


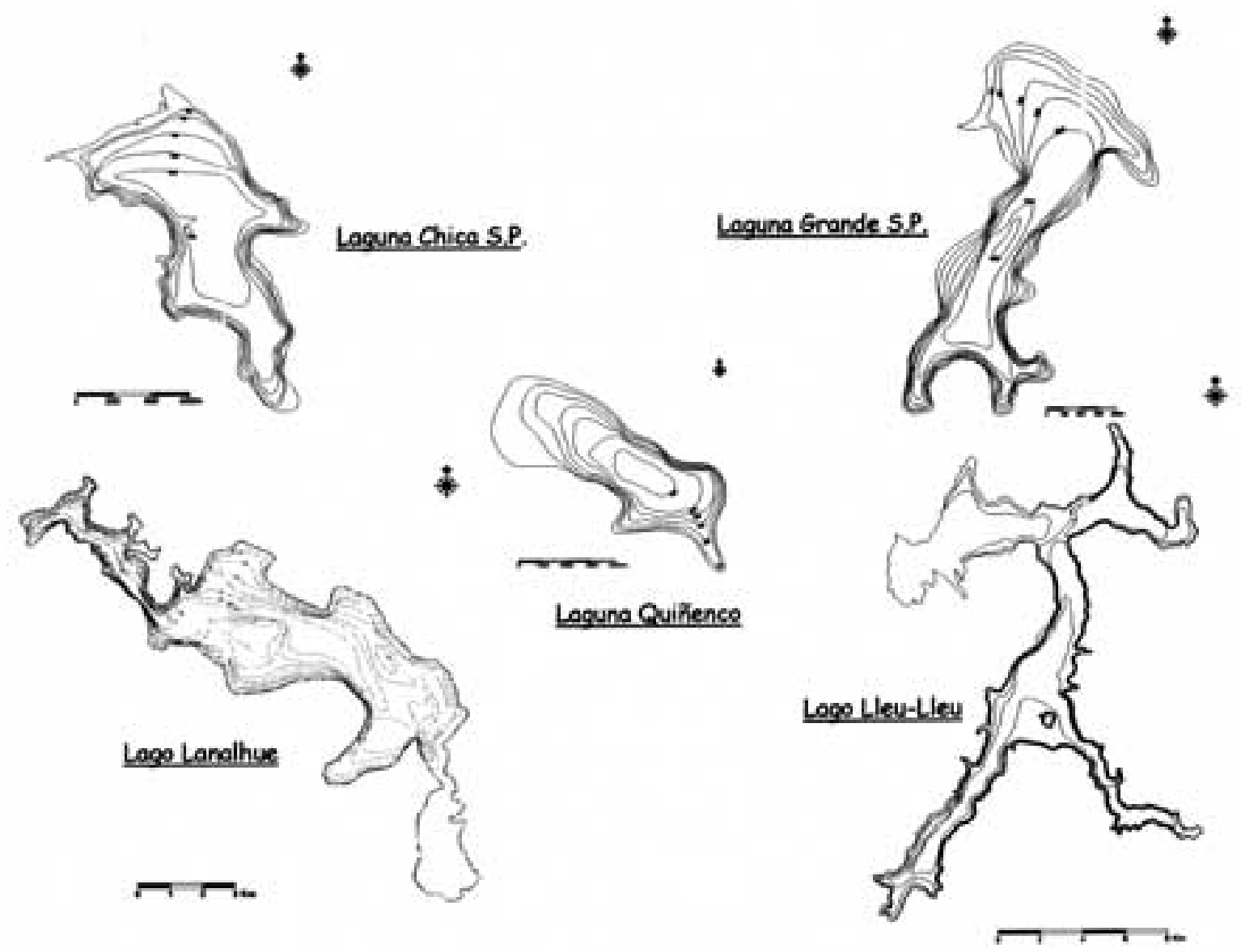

Figura 3. Batimetría de los cuerpos de agua. Bathymetry of the water bodies.

(Cryptocarya alba), "Boldo" (Peumus boldus), "Avellano" (Gevuina avellana), "Litre" (Lithrea caustica), "Maqui" (Aristotelia chilensis) y Canelo (Drymis winteri). En los últimos años la vegetación presenta una tendencia notoriamente degradativa hacia comunidades del tipo matorral y pastizal, degradación que se traduce en erosión de los suelos (Barrientos, 1990).

Los usos del suelo de los cinco lagos son: a) bosque y matorral nativo, generalmente una forma degradada de bosque, debido a la temprana intervención humana (e.g. corta y quemas), b) plantaciones forestales, áreas ocupadas por plantaciones forestales principalmente $P$. radiata y Eucalyptus globulos, c) áreas deforestadas con escasa o nula cobertura vegetal generadas por diversas intervenciones humanas (corta, quemas, incendios), con suelos expues- tos, d) áreas con sectores de humedales y e) áreas con cobertura urbana y residencial. La Tabla 1 presenta un cuadro comparativo de los usos del suelo de las respectivas cuencas de drenaje de los lagos estudiados.

Por otra parte es necesario indicar que la actividad forestal en la Región, basada mayormente en plantaciones de especies exótica, es el carácter dominante en el paisaje, ocupando cerca del $40 \%$ de todo el territorio regional y más del $50 \%$ del área de estudio. Al mismo tiempo representa la principal actividad económica en cuanto a usos de recursos naturales.

\section{Morfometría y batimetría}

La morfología de los lagos estudiados presentó un amplio rango de variación tanto en forma 
como tamaño (Fig. 3). Es así que el tamaño de los lagos fluctuó entre $39.8 \mathrm{~km}^{2}$ (Lleulleu) y los $3.0 \mathrm{~km}^{2}$ (Quiñenco) de superficie, con profundidades que fluctuaron entre $\operatorname{los} 46.5 \mathrm{~m}$ (Lleulleu) y $6.1 \mathrm{~m}$ (Quiñenco). Por su parte la forma fluctuó entre contornos muy regulares, con bajo desarrollo de costa, como el caso de laguna Quiñenco (1.5, Laguna Chica (1.8) y Laguna Grande (2.1) de San Pedro, hasta formas y contornos muy irregulares, representados por altos valores de desarrollo de línea de costa de los lagos Lleulleu (4.2) y Lanalhue (2.9).

La poca profundidad de los lagos estudiados es consistente con la uniformidad geológica del área y la escasa altura del relieve donde se encuentran ubicados (Mardones \& Reuther, 1999). Sólo el Lago Lleulleu presentó una profundidad máxima superior a los $30 \mathrm{~m}$. Estos resultados indican que todos los lagos, con excepción del Lleulleu, presentan el 100\% de su área sobre la cota que determina la zona de aguas someras que según Campos et al., (1992) está determinada por la isóbata de los $30 \mathrm{~m}$. El lago Lleulleu presentó una zona de aguas someras que corresponden aproximadamente al 50\% de su área total. La batimetría de estos cuerpos de agua esta estrechamente asociado al origen de cubetas que contienen las masas de agua. Los lagos Quiñenco, Chica y Grande de San Pedro presentan una sola gran cubeta de fondo plano, que ocupa la mayor extensión en superficie, con fuertes pendientes en las riberas asociadas a la cordillera de Nahuelbuta y una suave batimetría hacia el extremo opuesto. En cambio la batimetría de los lagos Lanalhue y Lleulleu esta determinado por el origen tectónico de estos cuerpos de agua. Es posible encontrar una completa caracterización morfométrica de los lagos en Urrutia et al., (2000), (Tabla 2).

\section{Caracterización sedimentológica}

Los sedimentos de los cinco lagos estudiados se caracterizaron por presentar texturas fangosas (limos y arcillas) muy homogéneas, con ausencia de fracciones gruesas (arenas y gravas). En todos los casos se trata de fangos sin características reductoras, de colores "Grises medianamente oscuros" (N4) con tonalidades "Gris café" (5YR4/1) y "Gris oliva" (5Y4/1), de acuerdo a la Carta de Colores de la Geological Society of América (1975).

Considerando el tamaño medio de las partículas de sedimento, el fango de todos los lagos se clasificó texturalmente (Wentworth, 1922) como "limos finos". Por otra parte y de acuerdo

Tabla 2. Características morfométricas de los lagos. Lakes' morphometric characteristics.

\begin{tabular}{lccccc}
\hline PARAMETROS & L. CHICA & L. GRANDE & L. QUIÑNCNO & L. LANALHUE & L. LLEU-LLEU \\
\hline Latitud (S) & $36^{\circ} 51^{\prime}$, & $36^{\circ} 51^{\prime}$ & $36^{\circ} 59^{\prime}$ & $37^{\circ} 55^{\prime}$ & $38^{\circ} 09^{\prime}$ \\
Longitud (W) & $73^{\circ} 05^{\prime}$ & $73^{\circ} 06^{\prime}$ & $73^{\circ} 07^{\prime}$ & $73^{\circ} 19^{\prime}$ & $73^{\circ} 19^{\prime}$ \\
Altura (m.s.n.m.) & 5.0 & 4.0 & 5.0 & 12.0 & 20.0 \\
Profundidad máx. (m) & 18.0 & 13.5 & 6.1 & 26.0 & 46.5 \\
Profundidad media (m) & 10.3 & 8.3 & 3.0 & 13.1 & 23.5 \\
Largo máx. (km) & 1.9 & 2.7 & 1.1 & 9.6 & 13.2 \\
Ancho máx. (km) & 0.87 & 1.4 & 0.36 & 4.3 & 3.7 \\
Perímetro (km) & 5.7 & 9.4 & 2.94 & 58.6 & 93.3 \\
Area del lago (km $\left.{ }^{2}\right)$ & 0.82 & 1.55 & 0.29 & 31.9 & 39.8 \\
Area cuenca (km ${ }^{2}$ ) & 4.5 & 12.7 & 3.0 & 325.0 & 670.0 \\
Volumen (km ${ }^{3}$ ) & 0.0086 & 0.0128 & 0.0009 & 0.418 & 0.934 \\
Desarrollo línea de costa & 1.8 & 2.1 & 1.5 & 2.9 & 4.2 \\
Rel. Prof. media / Prof. máx. & 0.57 & 0.61 & 0.49 & 0.50 & 0.50 \\
Rel. Área cuenca / área lago & 5.5 & 8.2 & 10.3 & 10.2 & 16.8 \\
Rel. Área cuenca / vol. lago & 523.3 & 992.2 & 3333.3 & 777.5 & 717.3 \\
Prof. criptodepresión (m) & 13.0 & 9.5 & 1.1 & 14.0 & 26.9 \\
\hline
\end{tabular}


Tabla 3. Parámetros granulométricos, texturales y Materia Orgánica Total (MOT) promedio de los lagos estudiados. Granulometric parameters, texture and Total Organic Matter (TOM) means for the studied lakes.

\begin{tabular}{lccccc}
\hline Lagos & Total estaciones & Tamaño Medio (phi) & Selección (phi) & Asimetría & MOT (\%) \\
\hline L. Chica & 24 & 6.57 & 0.79 & -0.13 & 14.8 \\
L. Grande & 28 & 6.51 & 0.81 & -0.18 & 20.0 \\
L. Quiñenco & 27 & 6.59 & 0.84 & -0.26 & 21.8 \\
L. Lanalhue & 44 & 6.48 & 0.80 & -0.06 & 14.7 \\
L. Lleu-Lleu & 81 & 18.3 & 6.57 & 0.83 & 18.3 \\
\hline
\end{tabular}
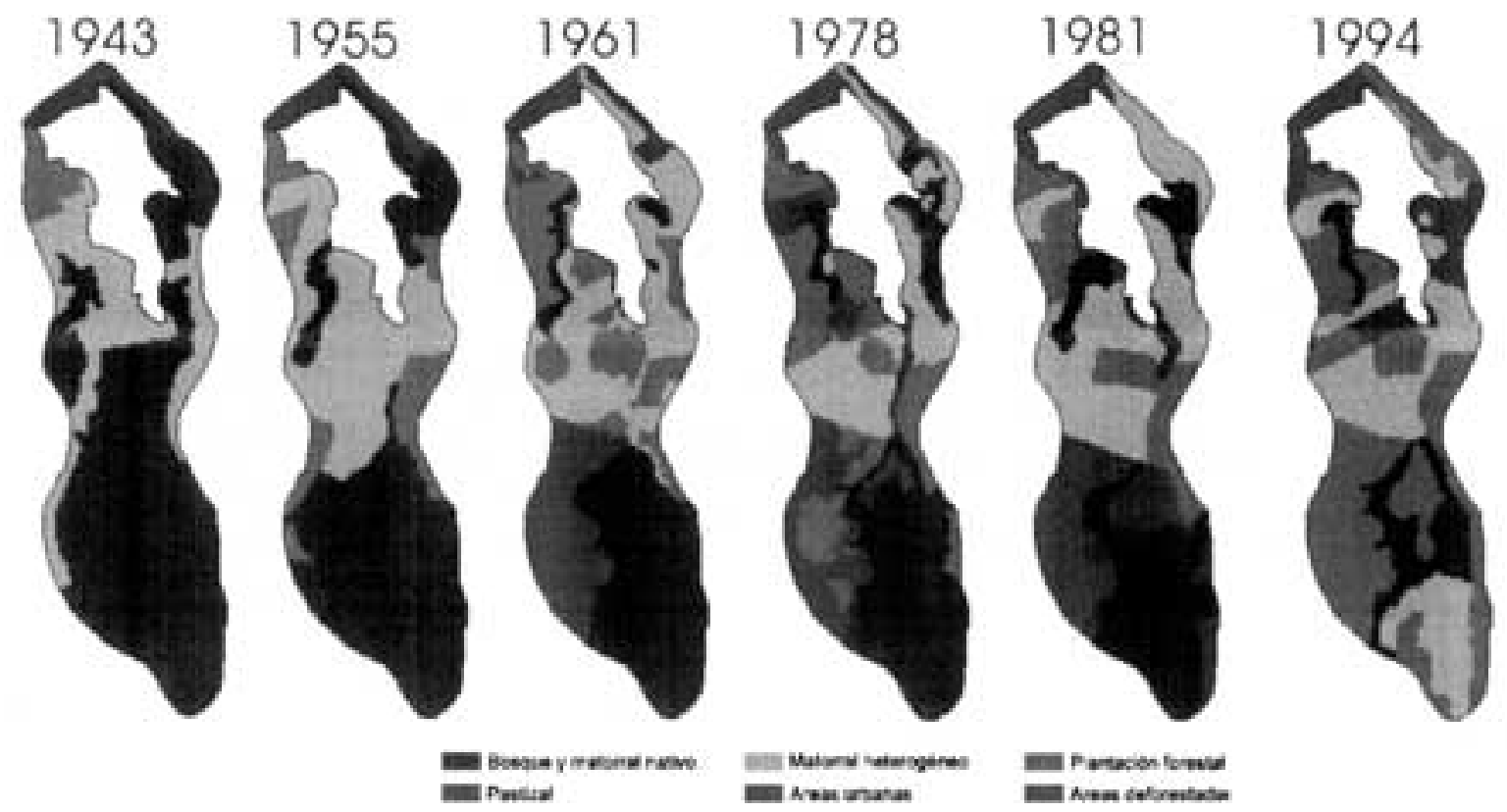

Figura 4. Evolución del uso del suelo en Laguna Chica de San Pedro. Soil use evolution in Laguna Chica de San Pedro.

al grado de selección de los granos, estos se ubican en el rango "moderadamente seleccionados". El parámetro de asimetría presentó una mayor variabilidad; sin embargo, todos los valores fueron negativos (Tabla 3). Mayor información sobre las características sedimentológicas se encuentra en Urrutia et al. (2000) y Valdovinos \& Figueroa (2000).

\section{Uso histórico del Uso del Suelo}

En los estudios de Cisternas et al., (1999, 2000, 2001), Mardones \& Reuther (2000) se reconocieron seis categorías de uso del suelo: i) bosque y matorral nativo, ii) matorral hete- rogéneo, iii) áreas deforestadas, iv) plantaciones forestales, v) áreas urbanas y residenciales, y vi) pastizales.

La figura 4 muestra la evolución del uso histórico del suelo en la cuenca de Laguna Chica. Se aprecia una sostenida disminución de la vegetación nativa, que hacia 1994, queda reducida a las quebradas más estrechas y profundas de la cuenca. Contrariamente, las plantaciones forestales muestran un continuo incremento. Entre 1961 y 1981, las áreas deforestadas presentan una importante extensión superficial. El uso residencial aparece por primera vez en 1961 y se mantiene relativamente estable hasta 1994 (Cisternas et al., 1999 a, b). 
Respecto al Cambio Total, la figura 5 muestra las áreas que modificaron su uso entre los periodos estudiados. Se aprecia un incremento de las modificaciones con el tiempo, del mismo modo, se reconoce que el cambio se fue trasladando hacia el sur, a los sectores de altas pendientes (Cisternas et al., 1999 a, b). La Figura 6 muestra el total de modificaciones ocurridas entre 1943 y 1994. Se observa que la casi la totalidad de la superficie de la cuenca fue transformada en un periodo de 50 años.

Considerando estas tendencias y la evolución histórica de la vertiente occidental de la cordillera de Nahuelbuta, es posible inferir que las cinco cuencas lacustres sufrieron un proceso de reemplazo de la vegetación nativa de un modo similar al reconocido para Laguna Chica. De este modo, Cisternas et al., (1999 b) proponen un modelo de reemplazo de vegetación nativa por plantaciones forestales para toda la cordillera de Nahuelbuta (Fig. 7). El Periodo I, representado por los años cuarenta, muestra una cobertura de bosque y matorral nativo degradado, minoritariamente en los sectores planos y mayoritariamente en las áreas de pendientes. Con el avance de las plantaciones (Periodo II), principalmente ubicadas en lugares llanos, los remanentes de nativo están limitados sólo a los sectores altos (probablemente por las dificultades de explotación). A diferencia de la rápida transición en los dos primeros periodos, el Periodo III presenta áreas deforestadas, que se mantienen por largo tiempo en los sectores más frágiles de las cuencas (Periodos III-IV). Finalmente, el propio proceso de forestación hará desaparecer las áreas deforestadas (Periodo V), quedando las cuencas completamente cubiertas con las plantaciones exóticas.

\section{Cambios en las tasas de erosión y sedimentación}

En la figura 8 es posible observar los resultados del análisis cronológico para Laguna Chica. Tanto el ${ }^{137} \mathrm{Cs}$ como la concentración de polen de $P$. radiata comprueban el modelo cronológico propuesto (Cisternas et al., 2001). De acuerdo con el modelo cronológico utilizado (CRS) la tasa neta de acumulación de sedimentos de Laguna Chica ha variado en un orden de magnitud, desde $50 \mathrm{~g} \mathrm{~m}^{-2} \mathrm{a}^{-1}$ hacia 1883 a $600 \mathrm{~g} \mathrm{~m}^{-2} \mathrm{a}^{-1}$ en 1968. Los cambios en las tasas de sedimentación muestran tres pulsos durante el s. XX. El primero comienza a fines del s. XIX y alcanza su máximo al final de los años cuarenta $\left(580 \mathrm{~g} \mathrm{~m}^{-2}\right.$ $\left.\mathrm{a}^{-1}\right)$. Otro pulso comienza a inicios de los años cincuenta $\left(240 \mathrm{~g} \mathrm{~m}^{-2} \mathrm{a}^{-1}\right)$ y alcanza su máximo a
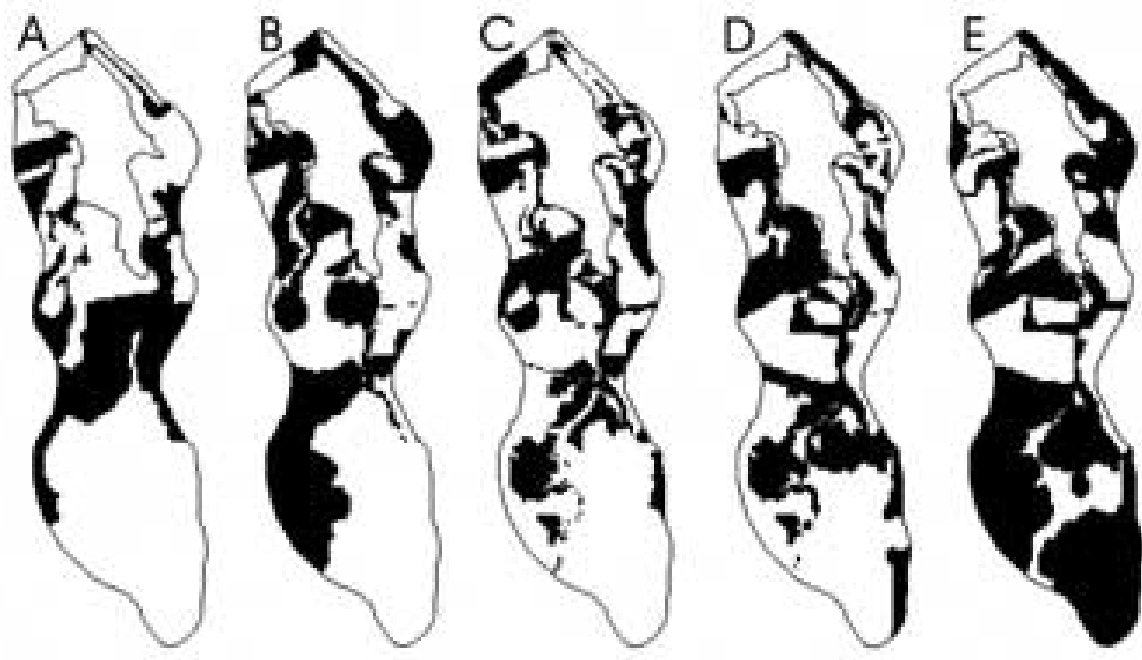

Figura 5. Evolución del Cambio Total durante los intervalos temporales estudiados $(\mathrm{A}=1943-1955 ; \mathrm{B}=1955-1961 ; \mathrm{C}=1961-$ $1978 ; \mathrm{D}=1978-1981 ; \mathrm{E}=1981-1994)$. Total change evolution during the studied temporal intervals $(A=1943-1955 ; B=1955$ 1961; $C=1961-1978 ; D=1978-1981 ; E=1981-1994)$. 
finales de los sesenta $\left(600 \mathrm{~g} \mathrm{~m}^{-2} \mathrm{a}^{-1}\right)$. El evento más reciente comienza alrededor de 1978 (260 g $\left.\mathrm{m}^{-2} \mathrm{a}^{-1}\right)$ y continua en los noventa, cuando el máximo fue $520 \mathrm{~g} \mathrm{~m}^{-2} \mathrm{a}^{-1}$ (Cisternas et al., 2001). En Chile, como en el resto del hemisferio sur, no se detectaron aumentos de las concentraciones de ${ }^{137} \mathrm{Cs}$ ambiental por efecto del accidente de Chernobyl ocurrido en Ucrania en 1986 (Surface Air Sampling Program; Larsen et al., 1995). En un monitoreo realizado en Chile entre los años 1966-1994 (Piñones \& Tomicic, 1995), no se detectaron los efectos de dicho accidente nuclear. Del mismo modo, análisis realizados en sedimentos de la Antártica (Appleby et al., 1995) no se reconocieron indicios de fallout radioactivo generado por dicho accidente. Lo anterior, se debe a que la inyección de ${ }^{137} \mathrm{Cs}$ en Chernobyl no fue de una magnitud suficiente para incorporarse a la estratosfera. De este modo, la contaminación no fue transportada a escala planetaria, afectando principalmente al norte de Europa (Larsen et al., 1995). Considerando lo anterior, el peak detectado en la columna sedimentaria de Laguna Chica de San Pedro, debe responder más bien al máximo de emisión estratosférica de 1963.

La erosión en la cuenca del lago fue calculada como $S^{*} A_{L} / A_{W}$, donde $S$ es la tasa de sedimentación calculada para el core, $\mathrm{A}_{\mathrm{L}}$ es el área del fondo del lago, y $A_{\mathrm{W}}$ el área de la cuenca hídrica (Cisternas et al., 2001). Se obtuvieron las tasas de erosión para los 10 primeros centímetros del núcleo (1942-1996). El registro de lluvia para el área (Figura 9 A) muestra que las precipitaciones no han tenido una tendencia a aumentar o disminuir durante los últimos 50 años. De este modo, es posible inferir que las variaciones en la erosión de la cuenca han estado controladas principalmente por el uso de suelo. Este mismo periodo temporal es cubierto por la información de uso del suelo obtenida más arriba. La tasa de erosión, a escala linear de tiempo (Figura $9 \mathrm{~B}$ ), presenta los mismos tres máximos que las tasas de sedimentación; sin embargo la escala linear muestra que fueron breves. Los primeros dos peaks, alrededor de 1950 y 1970, duraron unos pocos años; el tercer máximo en los años noventa, dura 7 años. Los

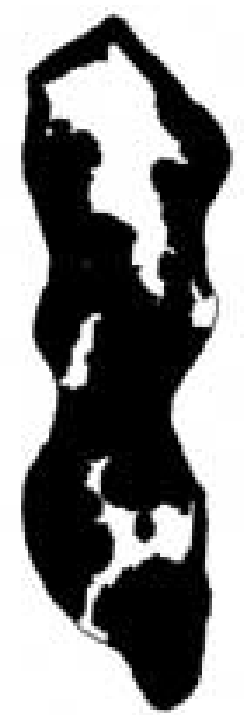

Figura 6. Total de modificaciones ocurridas entre 1943 y 1994. Total changes occured between 1943 and 1994.

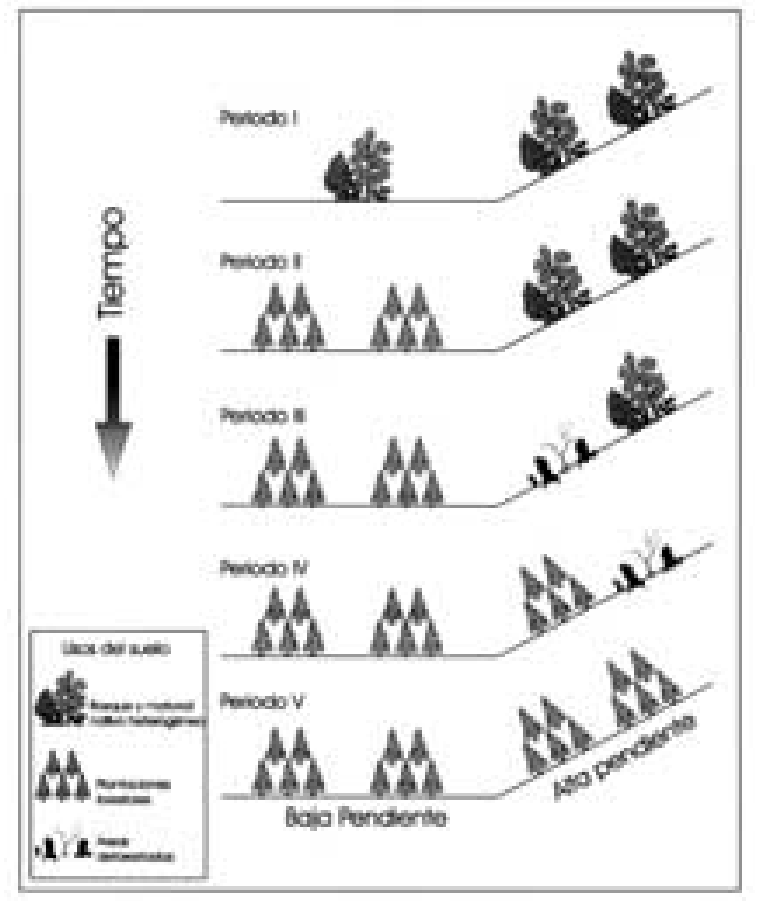

Figura 7. Modelo conceptual del proceso de cambio de uso del suelo para la cordillera de Nahuelbuta (Cisternas et al., 1999 b). Conceptual model of the soil use change process for the Nahuelbuta range (Cisternas et al., 1999 b)

tres máximos se aproximan a $1 \mathrm{tm} \mathrm{ha}^{-1} \mathrm{a}^{-1}$. Valores bajo la media $\left(0.5 \mathrm{tm} \mathrm{ha}^{-1} \mathrm{a}^{-1}\right)$ predominan por periodos más largos (Cisternas et al., 2001). 
Caracterización de cinco lagos costeros chilenos

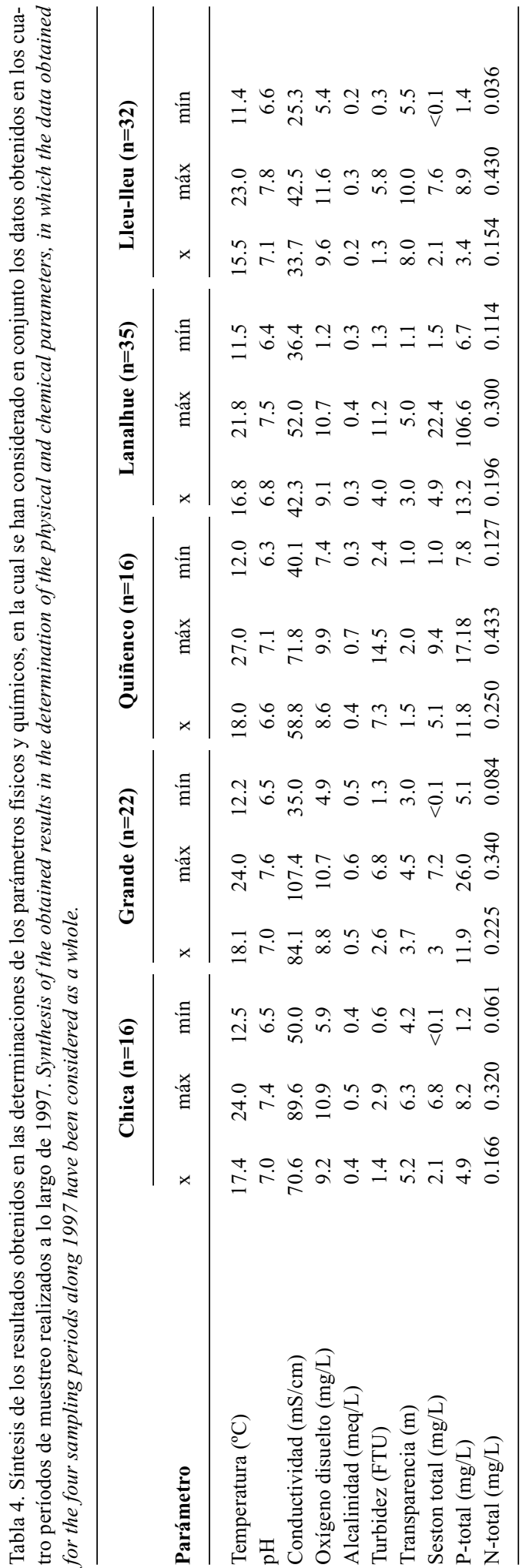


La figura 9C muestra las relaciones detectadas entre el uso del suelo y las tasas de erosión. Más que la tipología de uso, el cambio total resultó ser el parámetro con mejor explicación. Se observa que modificaciones en el cambio total se traducen en incrementos en las tasas de erosión (Cisternas et al., 2001). La Figura 9 D presenta la correlación obtenida entre ambas variables $\left(r^{2}=0.95\right)$.

\section{Comparación entre las condiciones prehispánicas y actuales}

La comparación realizada entre sedimentos prehispánicos y actuales de los lagos estudiados, indican que han sufrido drásticas transformaciones desde la llegada de los españoles, evolucionando, de acuerdo al polen, desde una cobertura vegetacional natural a una fuerte presión de uso forestal (Cisternas et al., 2000). Del mismo modo, el estudio cualitativo del agua, a través de las diatomeas, reconoce un cambio en sus características tróficas; desde aguas oligotróficas a eutróficas en Laguna Grande, y desde oligotrofía a mesotrofía en Laguna Chica (Urrutia et al., 2000).

\section{Calidad del agua}

En la Tabla 4 se presenta una síntesis de los resultados obtenidos en las determinaciones de los parámetros físicos y químicos, en la cual se han considerado en conjunto los datos obtenidos en los cuatro períodos de muestreo realizados a lo largo de 1997. El número total de muestras que se integró para cada lago fue el siguiente: Laguna Chica de San Pedro n=16, Laguna Grande de San Pedro $\mathrm{n}=22$, Laguna Quiñenco $\mathrm{n}=16$, Lago Lanalhue $\mathrm{n}=35$ y Lago Lleu-lleu $\mathrm{n}=32$. Considerando la serie de 5 lagos, los rangos de variación por parámetro son los siguientes: temperatura 11.4-27.0 ${ }^{\circ} \mathrm{C}, \mathrm{pH}$ 6.3-7.8, conductividad 25.3-107.4 $\mu \mathrm{S} / \mathrm{cm}$, oxígeno disuelto $1.2-11.6 \mathrm{mg} / \mathrm{L}$, alcalinidad $0.2-$ $0.7 \mathrm{meq} / \mathrm{L}$, turbidez $0.3-14.5 \mathrm{FTU}$, transparencia $1-10 \mathrm{~m}$, seston total $<0.1-22.4 \mathrm{mg} / \mathrm{L}$, P-total 1.4$106.6 \mu \mathrm{g} / \mathrm{L}$ y N-total $0.036-0.430 \mathrm{mg} / \mathrm{L}$.

El Lago Lleulleu y la Laguna Chica de San Pedro presentan una buena calidad de agua considerando, los valores de la transparencia, del seston, oxígeno disuelto y las concentraciones de fósforo y nitrógeno, mientras que considerando los valores que alcanzan los mis-

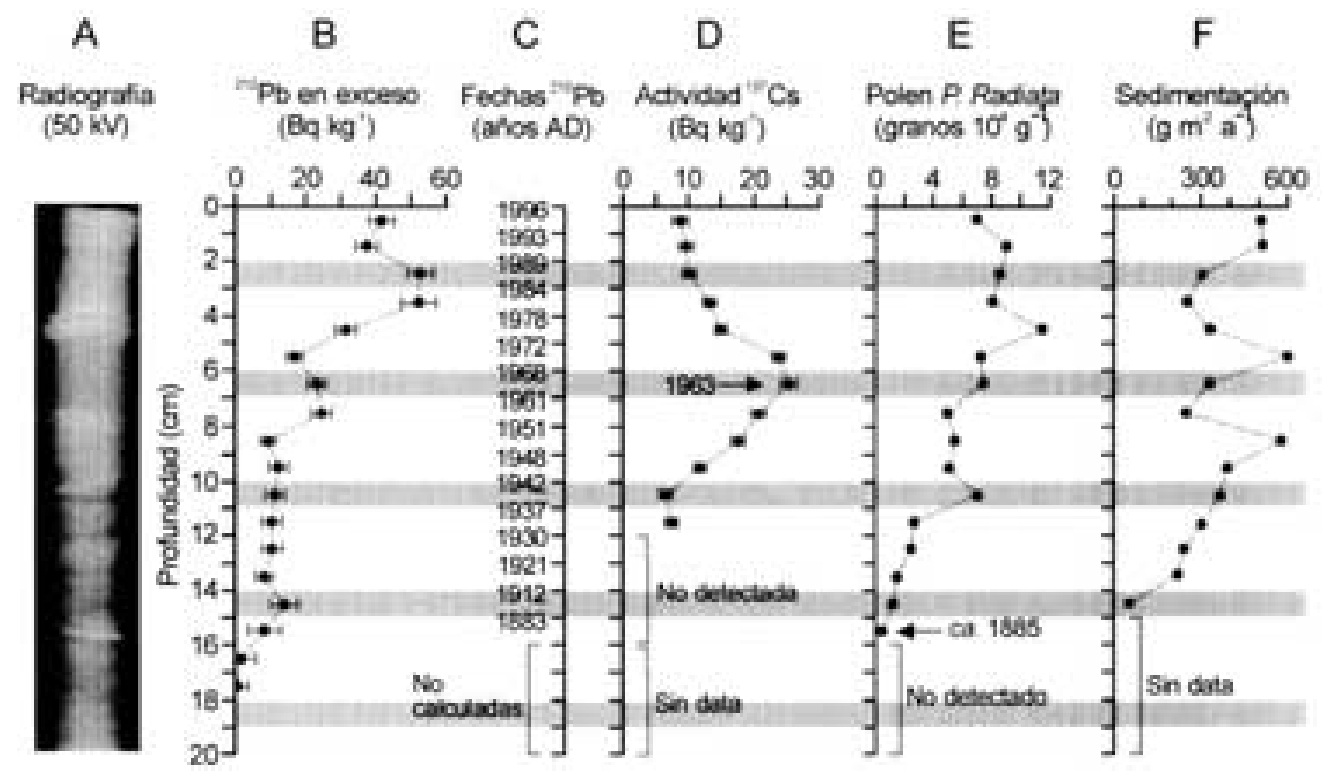

Figura 8. Radiografía (A), actividad de ${ }^{210} \mathrm{~Pb}$ en exceso (B), modelo cronológico (C), actividad de ${ }^{137} \mathrm{Cs}$ (D), concentración de polen de $P$. radiata (E), tasas de sedimentación (F) del registro sedimentario de Laguna Chica (Cisternas et al., 2001). X-Ray (A), activity of ${ }^{210} \mathrm{~Pb}$ in excess $(B)$, chronologic model $(C),{ }^{137} \mathrm{Cs}$ activity $(D)$, P. radiata pollen concentration $(E)$, sedimentation rates (F) of the sedimentary record of Laguna Chica (Cisternas et al., 2001) 
mos parámetros en las lagunas Quiñenco y Grande de San Pedro, y el Lago Lanalhue, ellas presentan una moderada calidad de agua (Tabla 4). Las variables asociadas a la entrada de sólidos en suspensión debido a la erosión de sus cuencas de drenaje, afectan a todos los sistemas estudiados, aunque en diverso grado. Los sistemas más afectados por este proceso corresponde a la Laguna Quiñenco y al Lago Lanalhue.

Tabla 5. Cuadro comparativo de la comunidad fitoplanctónica de los 5 lagos. Comparative chart of the phytoplancton community for the five lakes.

\begin{tabular}{|c|c|c|c|c|c|}
\hline $\begin{array}{l}\text { Parámetros } \\
\text { Comunitarios }\end{array}$ & $\begin{array}{l}\text { Laguna Chica } \\
\text { de San Pedro }\end{array}$ & $\begin{array}{l}\text { Laguna Grande } \\
\text { de San Pedro }\end{array}$ & $\begin{array}{l}\text { Laguna } \\
\text { Quiñenco }\end{array}$ & $\begin{array}{l}\text { Lago } \\
\text { Lanalhue }\end{array}$ & $\begin{array}{l}\text { Lago } \\
\text { Lleu-Lleu }\end{array}$ \\
\hline Riqueza específica & 39 & 57 & 39 & 48 & 44 \\
\hline Grupos taxonómicos & Bacillariophyceae & Chlorophyceae & Chlorophyceae & Bacillariophyceae & Bacillariophyceae \\
\hline con mayor riqueza & Chlorophyceae & Bacillariophyceae & Bacillariophyceae & Chlorophyceae & Chlorophyceae \\
\hline de especies & Cyanophyceae & Cyanophyceae & Chrysophyceae & Cyanophyceae & Cyanophyceae \\
\hline Taxa Cyanophyceae & 4 & 3 & 1 & 5 & 5 \\
\hline Taxa Chrysophyceae & 1 & 1 & 2 & 3 & 1 \\
\hline Taxa Xanthophyceae & - & - & - & - & - \\
\hline Taxa Dinophyceae & 2 & - & 1 & 3 & 2 \\
\hline Taxa Cryptophyceae & 2 & 3 & 1 & 2 & 3 \\
\hline Taxa Euglenophyceae & - & - & 2 & - & - \\
\hline Taxa Bacillariophyceae & 15 & 19 & 10 & 20 & 24 \\
\hline Taxa Chlorophyceae & 15 & 31 & 22 & 15 & 9 \\
\hline Taxa Desmideaceae & 9 & 13 & 16 & 4 & - \\
\hline Taxa marinos & - & - & - & 3 & 3 \\
\hline $\begin{array}{l}\text { Indice acumulativo } \\
\text { fitoplantónico }\end{array}$ & 4.33 & 4.38 & 2.43 & 12.0 & - \\
\hline Especies más frecuentes & $\begin{array}{l}\text { M. elachista } \\
\text { G. lacustris } \\
\text { Cymbella sp. } \\
\text { Navicula sp. } \\
\text { Di. subovalis } \\
\text { S. schroeteri }\end{array}$ & $\begin{array}{l}\text { M. aeruginosa. } \\
\text { Mallomonas sp. } \\
\text { A. formosa } \\
\text { A. granulata } \\
\text { Fragilaria sp. } \\
\text { M. distans } \\
\text { S. tenera } \\
\text { C. acutum } \\
\text { S. ecornis } \\
\text { S. dejectus } \\
\text { S. gracile } \\
\text { S. leptocladum }\end{array}$ & $\begin{array}{l}\text { Anabaena sp } \\
\text { Mallomonas sp. } \\
\text { A. granulata } \\
\text { S. tenera }\end{array}$ & $\begin{array}{l}\text { A. spiroides } \\
\text { M. wesembergii } \\
\text { R. lacustris } \\
\text { C. erosa } \\
\text { A. granulata } \\
\text { Fragilaria sp. } \\
\text { M. distans } \\
\text { Navicula sp. } \\
\text { C. acutum } \\
\text { O. lacustris } \\
\text { S. gracile } \\
\text { S. leptocladum }\end{array}$ & $\begin{array}{l}\text { C. limneticus } \\
\text { G. lacustris } \\
\text { Peridinium sp. } \\
\text { C. ovata } \\
\text { C. erosa. } \\
\text { A. granulata } \\
\text { N. viridula } \\
\text { Navicula sp. } \\
\text { Nitzschia } \mathrm{sp} \text {. } \\
\text { S. schroeteri }\end{array}$ \\
\hline $\begin{array}{l}\text { Especies más } \\
\text { abundantes }\end{array}$ & $\begin{array}{l}\text { S.schroeteri } \\
\text { M. elachista } \\
\text { Fragilaria sp. } \\
\text { Di. subovalis } \\
\text { Peridinium sp. }\end{array}$ & $\begin{array}{l}\text { M. distans } \\
\text { A. granulata } \\
\text { E. fotti } \\
\text { S. schroeteri } \\
\text { M. contortum }\end{array}$ & $\begin{array}{l}\text { A. granulata } \\
\text { G. monotaenium } \\
\text { Mallomonas sp. } \\
\text { D. divergens } \\
\text { X. antilopaeum } \\
\text { Anabaena sp. }\end{array}$ & $\begin{array}{l}\text { A. granulata } \\
\text { A. spiroides } \\
\text { M. varians } \\
\text { M. dikiei } \\
\text { S. schroeteri } \\
\text { M. distans } \\
\text { M. wesembergii }\end{array}$ & $\begin{array}{l}\text { A. granulata } \\
\text { G. lacustris } \\
\text { C. limneticus } \\
\text { D. divergens } \\
\text { M. elachista } \\
\text { Fragilaria } \mathrm{sp} \text {. }\end{array}$ \\
\hline promedio (cél. $\mathrm{L}^{-1}$ ) & 122957 & 487849 & 77515 & 495608 & 130328 \\
\hline $\begin{array}{l}\text { Máxima densidad celular } \\
\left.\text { y estación (cél. } \mathrm{L}^{-1}\right)\end{array}$ & $\begin{array}{l}340950 \\
\text { (verano) }\end{array}$ & $\begin{array}{l}1074230 \\
\text { (invierno) }\end{array}$ & $\begin{array}{l}77515 \\
\text { (primavera) }\end{array}$ & $\begin{array}{l}1135260 \\
\text { (invierno) }\end{array}$ & $\begin{array}{l}205147 \\
\text { (verano) }\end{array}$ \\
\hline
\end{tabular}




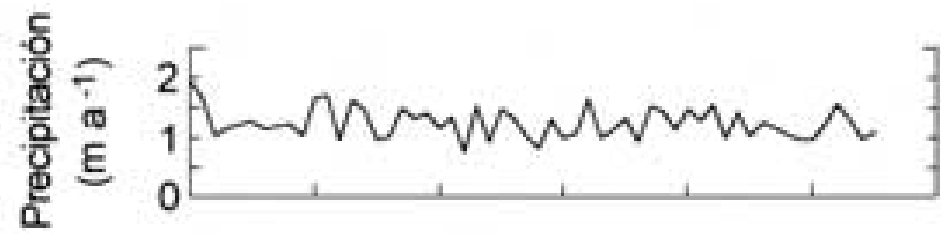

A
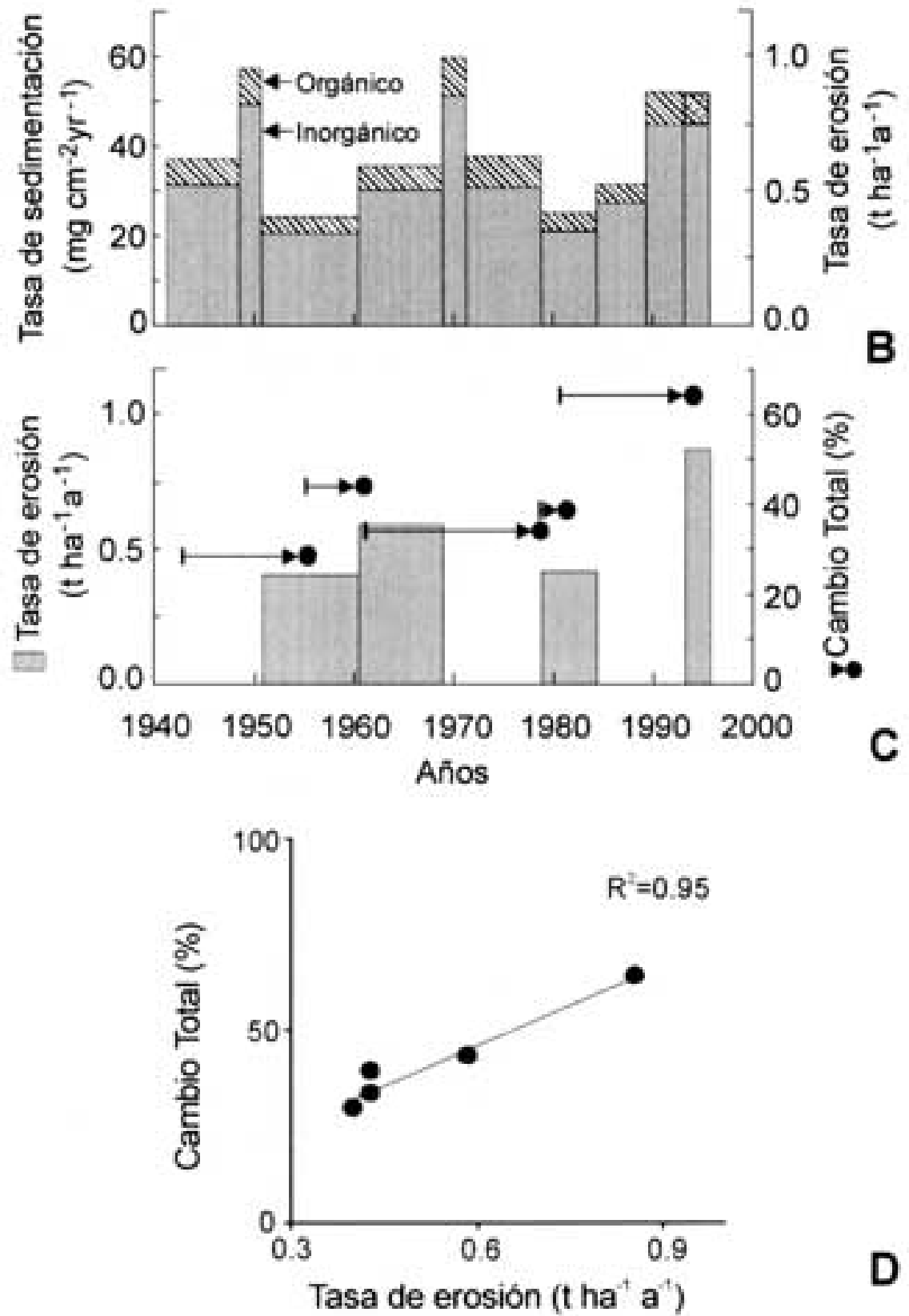

Figura 9. Registro de precipitación (A), tasa de sedimentación y tasa de erosión (B), relación entre Cambio Total y tasas de erosión (C) y correlación entre Cambio Total y erosión (D). Rainfall record (A), sedimentation and erosion rates (B), relationship between Total Change and erosion rates (C), and correlation between Total Change and erosion (D) 
Los contenidos de P-total en el agua del Lago Lleulleu y en la Laguna Chica de San Pedro son bajos, y moderados en la Laguna Quiñenco. Por el contrario las concentraciones de la Laguna Grande de San Pedro y del Lago Lanalhue son críticas, al favorecer una elevada producción de materia orgánica que produce condiciones hipóxicas en las aguas del fondo durante el período estival.

\section{Componentes biológicos}

\section{Fitoplancton}

Estudios previos sobre el fitoplancton de estos lagos corresponden a los de Parra et al., (1976, 1980, 1981, 1982, 1983, 1989) y Dellarossa \& Parra (1985). Estos estudios han permitido también comparar temporalmente las comunidades fitoplanctónicas para tres de los cinco lagos estudiados (Chica y Grande de San Pedro, Lanalhue).

La Tabla 5 resume las principales características referidas a la comunidad fitoplanctónica de estos lagos. El estudio de Parra et al., (1999) indica que de los tres cuerpos de aguas que poseían información sobre el fitoplancton, se ha detectado importantes cambios en la composición específica y abundancias relativas de las especies, especialmente en el caso de las Lagunas Chica y Grande de San Pedro y un leve cambio en el Lago Lanalhue. Estos cambios se han reflejado mayormente, en el grupo de las algas verdes o Chlorophyceae, y dentro de éste, particularmente en las Desmidiaceae, grupo muy sensible a cambios de condiciones ambientales, especialmente aquellos asociados a contaminación orgánica y eutroficación. En los mismos tres lagos se habían registrado floraciones acuáticas ("blooms"), los cuales no se detectaron en el presente estudio. Los "blooms" detectados anteriormente, han sido generados por especies del género Microcystis, que para el caso de Laguna Grande de San Pedro, correspondió a la especie M. aerugino$s a$, para el Lago Lanalhue $M$. wesenbergii y para la Laguna Chica de San Pedro, importantes abundancias de B. braunii. Esta situación es un indicio que las condiciones ambientales de éstos lagos han cambiado. Tanto en la Laguna Grande de San Pedro como en el Lago Lanalhue, los eventos de floraciones algales disminuyeron y en algunos años hasta el presente no se han desarrollado producto del control de las aguas servidas las cuales fueron desviadas de curso a partir de los años 1992 y 1993, respectivamente. Lo anterior también se ha reflejado en las mediciones de colimetrías fecales.

\section{Bentos}

Las comunidades bentónicas reaccionan drásticamente a las perturbaciones en el ambiente y son predecibles ante las influencias humanas sobre los
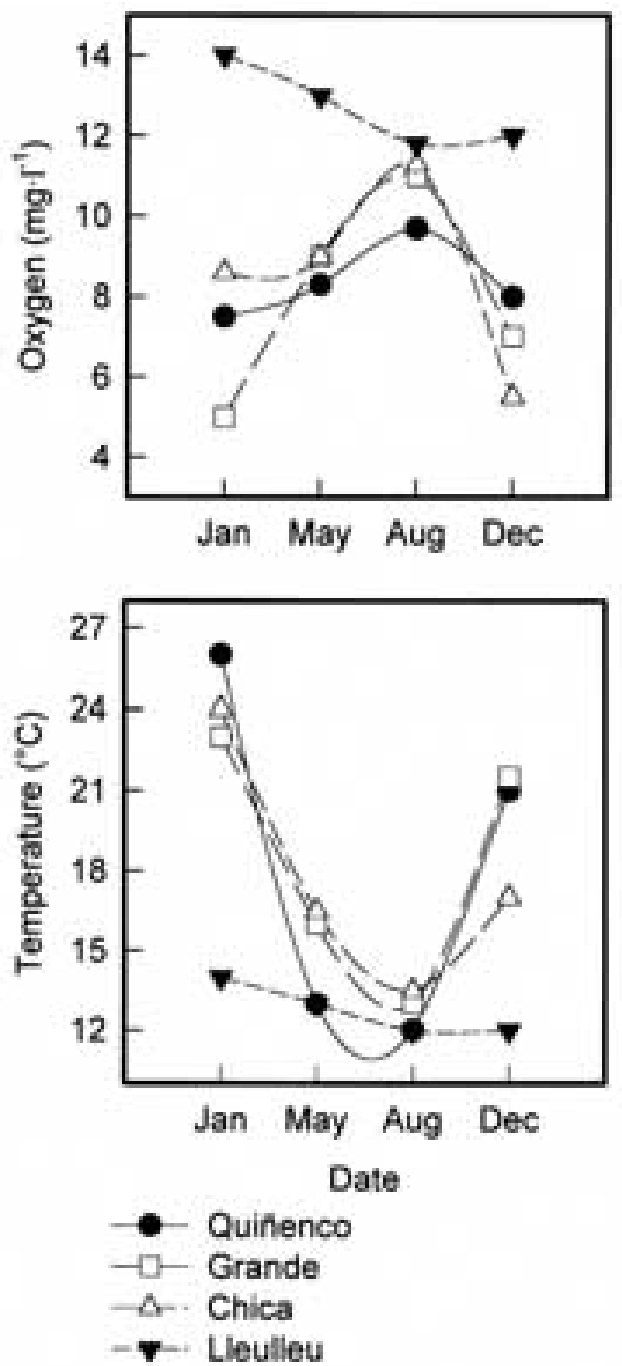

Figura 10. Variaciones anuales en las concentraciones de oxígeno $\left(\mathrm{mg} \mathrm{O}_{2} \cdot \mathrm{1}^{-1}\right)$ y temperatura $\left({ }^{\circ} \mathrm{C}\right)$ en las aguas de fondo de los lagos Grande de San Pedro, Chica de San Pedro, Quiñenco y Lleulleu. Annual variations in the oxygen concentrations ( $\left.\mathrm{mg} \mathrm{O}_{2} \cdot \mathrm{l}^{-1}\right)$ and temperature $\left({ }^{\circ} \mathrm{C}\right)$ in deep waters of Grande de San Pedro, Chica de San Pedro, Quiñenco and Lleulleu lakes. 
Tabla 6. Caracterización de los sedimentos superficiales (macroinvertebrados, granulometría, potencial redox (Eh) y carbono orgánico) y contenido de nutrientes de las aguas de fondo (P-total y N-total) de los lagos Quiñenco, Grande de San Pedro, Chica de San Pedro y Leulleu. Superficial sediments characterization (mcroinvertebrates, granulometry, redox potential,(Eh) and organic carbon), and nutrient content of benthic waters (Total-P and Total-N) for lakes Quiñenco, Grande de San Pedro, Chica de San Pedro, and Leulleu.

\begin{tabular}{|c|c|c|c|c|c|c|c|c|c|}
\hline & & \multicolumn{2}{|c|}{ Quiñenco } & \multicolumn{2}{|c|}{ Grande } & \multicolumn{2}{|c|}{ Chica } & \multicolumn{2}{|c|}{ Lleulleu } \\
\hline & & Core 1 & Core 2 & Core 1 & Core 2 & Core 1 & Core 2 & Core 1 & Core 2 \\
\hline Macroinvertebrados & $(>250 \mu \mathrm{m})$ & No & No & No & No & No & No & No & No \\
\hline Granulometría & (Phi medio) & 6.5 & 6.5 & 6.5 & 6.5 & 6.5 & 6.5 & 6.5 & 6.5 \\
\hline Potencial redox ${ }^{1}$ & $\mathrm{mV})$ & -250 & -270 & -350 & -310 & +45 & -10 & +200 & +170 \\
\hline Carbono orgánico & $(\%)$ & 25.3 & 28.5 & 21.4 & 22.5 & 15.3 & 19.0 & 14.0 & 17.1 \\
\hline Total-P & $\left(\mu \mathrm{g}^{-1}\right)$ & 35.6 & 35.0 & 52.0 & 52.4 & 16.4 & 16.1 & 4.76 & 4.70 \\
\hline Total-N & $\left(\mathrm{mg} \mathrm{l}^{-1}\right)$ & 0.86 & 0.84 & 0.68 & 0.60 & 0.64 & 0.65 & 0.07 & 0.07 \\
\hline
\end{tabular}

${ }^{1}$ bajo los primeros $50 \mathrm{~mm}$ de la columna de sedimento.

ecosistemas acuáticos, como es el caso de la eutroficación cultural (Rosenberg \& Resh, 1993). En el presente estudio, se analizó el efecto de la trofía de los sistemas lénticos, sobre la estructura de las comunidades de macroinvertebrados bentónicos. Los resultados muestran que el estado trófico de un lago tiene un importante efecto sobre las comunidades bentónicas. En la figura 12 se presenta un cuadro que resume la relación existente entre las características bióticas de los lagos y su nivel de trofía (niveles de materia orgánica de los sedimentos, y niveles de Seston orgánico, Ptotal y N-total). Nótese que los 5 lagos están ordenados en el espacio bidimensional de acuerdo a su macrofauna, coincidiendo con el incremento del nivel de trofía de los lagos siguiendo la secuencia: L. Lleulleu, L. Chica de San Pedro, L. Quiñenco, L. Grande de San Pedro y L. Lanalhue.

En la figura 13 se señalan las sucesiones de especies (o formas) responsables de la ordenación de las 23 estaciones de muestreo. La línea diagonal divide el NMDS en dos campos: el derecho incluye a las estaciones de fondos blandos (círculos blancos) y el izquierdo a las de fondos duros (círculos negros). Cada campo posee grupos característicos de taxa que están ordenados secuencialmente de acuerdo al nivel trófico de los lagos. En fondos duros de lagos pobres en nutrientes dominan Meriadialaris sp., Aegla sp. y Oligochaeta indet.3; mientras que en lagos ricos en nutrientes dominan Dugesia anceps, Arrenuridae indet., Micropsectra sp. y Chironomus sp. Por otra parte, en fondos blandos de lagos pobres en nutrientes dominan Diplodon chilensis y Pisidium chilense, mientras que en los más ricos en nutrientes, Oribatuloidea indet. y Chironomidae indet.3.

Los resultados del análisis de regresión múltiple entre las variables abióticas y bióticas (Tabla 7), indican que la agrupación de las estaciones de muestreo basándose en su macrofauna, es explicada fundamentalmente (en orden jerárquico) por el contenido de materia orgánica de los sedimentos, Seston orgánico, Seston total, Nitrógeno total, Fósforo total y Seston inorgánico.

Los resultados sugieren que: a) los factores abióticos de la columna de agua y sedimentos, afectan la estructura comunitaria de los macroinvertebrados bentónicos; b) existe una sucesión de especies a lo largo del gradiente de trofía de los lagos, tanto en fondos duros litorales como en fondo blandos sublitorales. En fondos duros de lagos pobres en nutrientes dominan Meriadialaris sp., Aegla sp. y Oligochaeta indet.3; mientras que en lagos ricos en nutrientes dominan Dugesia anceps, Arrenuridae indet., Micropsectra sp. y Chironomus sp. Por otra parte, en fondos blandos de lagos pobres en nutrientes dominan Diplodon chilensis y Pisidium chilense, mientras que en los más ricos en nutrientes, Oribatuloidea indet. y Chironomidae indet.3.

Las tasas de decaimiento de oxígeno disuelto en columnas de sedimento no perturbadas, han sido empleadas como una medida integradora de la actividad metabólica de las comunidades ben- 

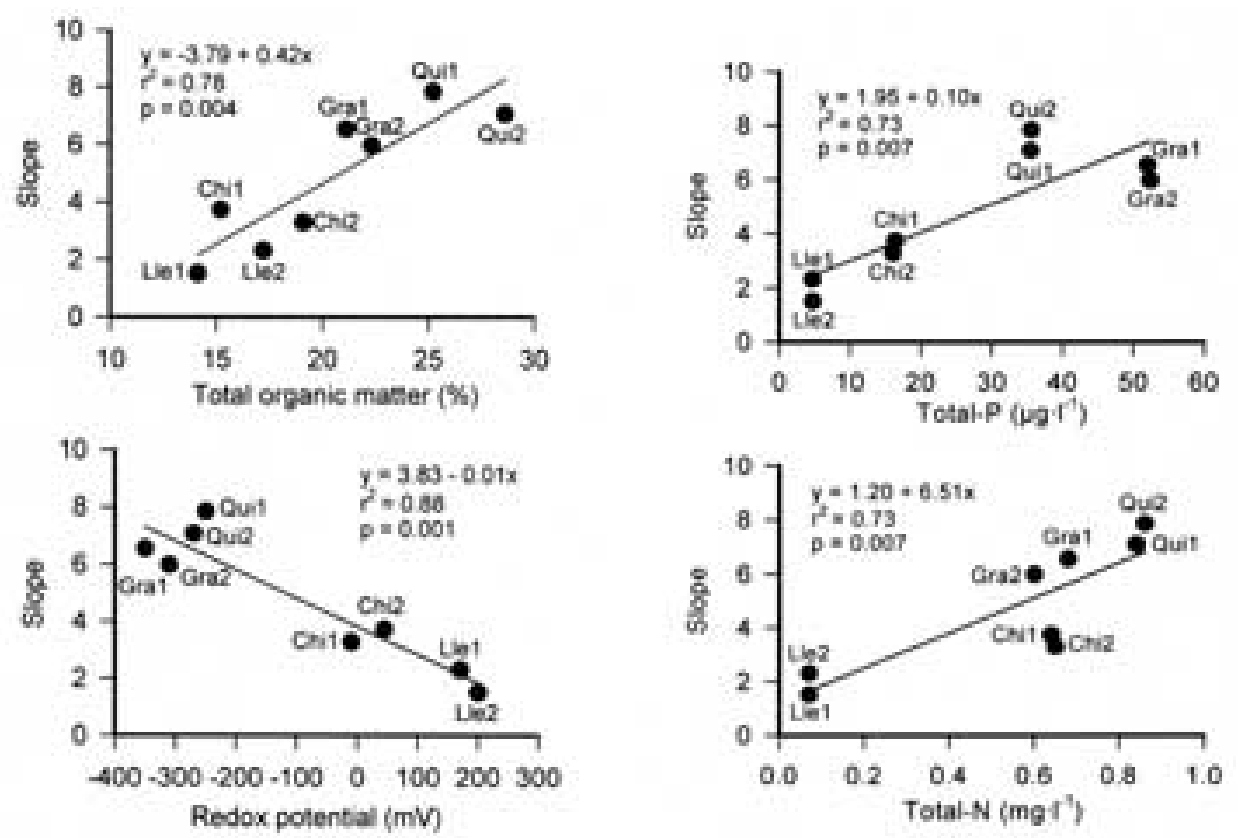

Figura 11. Relaciones entre las pendientes de las curvas de regresión de las tasas de consumo de oxígeno de cada core y las características de los sedimentos (material orgánica total y potencial redox) y de las aguas de fondo (fósforo y nitrógeno total). Chi= Chica, Gra= Grande, Qui= Quiñenco, Lle= Lleulleu, 1= core 1, 2= core 2. Relationships between regression curves' slopes for the oxygen consumption rates of each core and the sediment characteristics (total organic matter and redox potential), and those of deep waters (total phosphorous and nitrogen) Chi=Chica, Gra= Grande, Qui=Quinenco, Lle =Lleulleu, 1=core 1, $2=$ core 2.

tónicas de los lagos (Edwards \& Rolley,1965; Pamatmat \& Banse, 1969; Smith,1973; Margrave, 1976; Newrkla \& Gunatilaka, 1982). Debido a que la intensidad de los procesos metabólicos de la zona profundal de un lago es dependiente de la producción de materia orgánica en la zona pelágica, las tasas de decaimiento de oxígeno reflejan la condición trófica de todo el lago (Hayes \& MacAuley, 1959; Rybak, 1969; Margrave, 1973; Newrkla \& Gunatilaka, 1982).

Cuatro de los lagos estudiados, que difieren marcadamente en sus condiciones tróficas, presentan una serie de características que permiten la comparación de las tasas de decaimiento de oxígeno bajo diferentes condiciones de oxigenación: Quiñenco, Grande, Chica y Lleulleu. Al respecto, Valdovinos y Figueroa (2000), realizaron un estudio cuyo principal objetivo fue establecer las relaciones entre las características sedimentarias de lagos con diferentes condiciones tróficas, y las tasas de decaimiento de oxígeno causado por el componente bentónico. La caracterización de los sedimentos estudiados y de las aguas de fondo se presentan en la Tabla 6. Estos muestran claramente un gradiente en los valores de todos los parámetros analizados desde condiciones de oligotrofía (Leulleu) a eutrofia (Quiñenco). Con respecto a las variaciones anuales en las concentraciones de oxígeno $(\mathrm{mg} / \mathrm{L})$ y temperatura $\left({ }^{\circ} \mathrm{C}\right)$ en las aguas de fondo de los lagos, estos muestran un marcado comportamiento estacional, con valores más elevados en invierno y más bajos en verano. Los valores más bajos se corresponden con los lagos con mayores niveles de trofía, tales como en los lagos Quiñenco y Grande de San Pedro (Fig. 10).

Con respecto a las tasas de consumo de oxígeno de los sedimentos, los resultados mostraron que existe una clara correlación entre esta variable y el estrado trófico de los lagos (Fig. 11). A $8 \mathrm{mg}$ $\mathrm{O}_{2} \cdot 1^{-1}$ en la columna de agua de los cores estudiados, las tasas de consumo de oxígeno fueron: Quiñenco 51.2 - $56.0 \mathrm{mg} \mathrm{O}_{2} \mathrm{~m}^{2} \mathrm{~h}^{-1}$ (eutrófico), Grande 41.2 - $46.4 \mathrm{mg} \mathrm{O}_{2} \mathrm{~m}^{2} \mathrm{~h}^{-1}$ (mesotrófico), Chica $23.2-18.1 \mathrm{mg} \mathrm{O}_{2} \mathrm{~m}^{2} \mathrm{~h}^{-1}$ (mesotrófico), y 


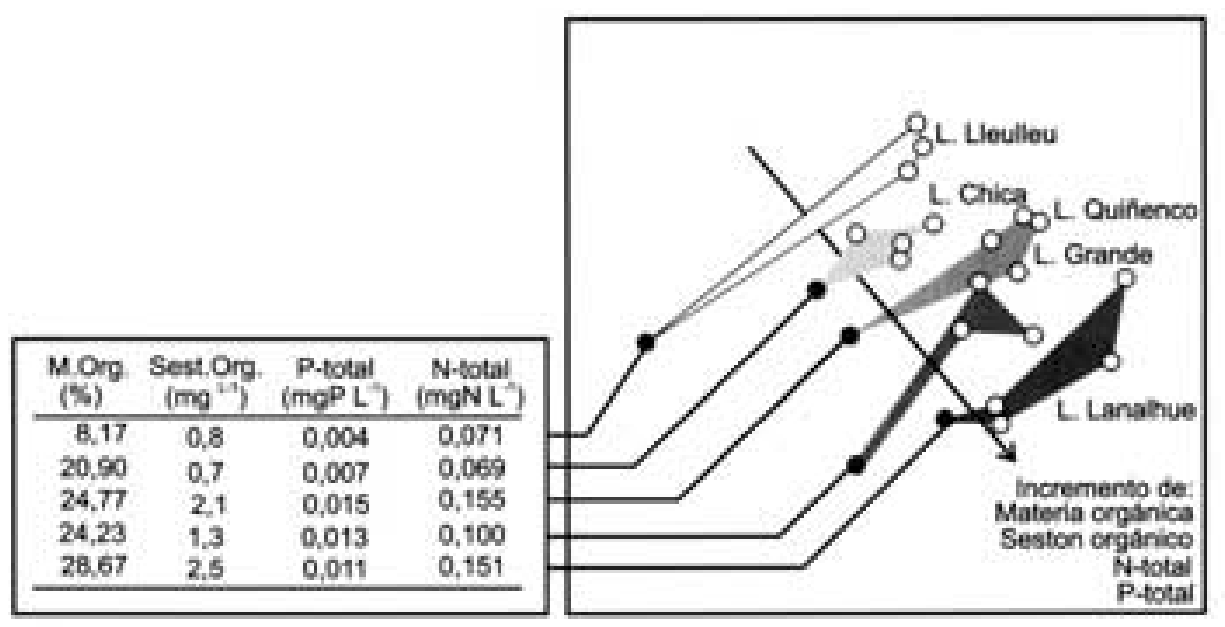

Figura 12. Ordenación de lagos en función de la biota bentónica y nivel de trofía. Lakes arrangement as a function of the benthic biota and trophic state.

Tabla 7. Regresión múltiple entre las variables abióticas y bióticas (valores de los dos primeros ejes del NMDS, que ordena las 23 estaciones de muestreo realizadas en los 5 lagos estudiados. $\mathrm{r}^{2}$-ajustado: coeficiente de determinación múltiple ajustado, el cual indica la fracción de la varianza explicada por una variable. Para ANOVA: ${ }^{*} p<0,05,{ }^{*} p<0,001$, n.s.: no significativa. Multiple regression between abiotic and biotic variables (values for the two first axes of the NMDS, that arranges the 23 sampling stations in the five studied lakes. Adjusted $r^{2}$ : adjusted multiple determination coefficient, which indicates the fraction of the variance explained by a variable. For ANOVA: *p $<0,05$, $*^{*} p<0,001$, n.s.: not significant.

\begin{tabular}{|c|c|c|c|c|c|}
\hline Variable & $\mathbf{r}^{2}$-ajustado & $\mathbf{F}$ & g.l. & $\mathbf{p}$ & \\
\hline \multicolumn{6}{|l|}{ Sedimento } \\
\hline Materia orgánica & 0.723 & 29.65 & 2.2 & 0.0000 & $* *$ \\
\hline \multicolumn{6}{|l|}{ Columna de agua } \\
\hline Seston orgánico & 0.619 & 18.84 & 2.2 & 0.0000 & $* *$ \\
\hline Seston total & 0.529 & 13.38 & 2.2 & 0.0002 & $* *$ \\
\hline Nitrógeno total & 0.504 & 12.18 & 2.2 & 0.0003 & $* *$ \\
\hline Fósforo total & 0.475 & 10.96 & 2.2 & 0.0006 & $* *$ \\
\hline Seston inorgánico & 0.404 & 8.46 & 2.2 & 0.0021 & $* *$ \\
\hline Alcalinidad & -0.002 & 0.98 & 2.2 & 0.3920 & n.s. \\
\hline
\end{tabular}

Lleulleu 11.7 - $16.0 \mathrm{mg} \mathrm{O}_{2} \mathrm{~m}^{2} \mathrm{~h}^{-1}$ (oligotrófico). Por otra parte, exponiendo en laboratorio los sedimentos a diferentes niveles de oxígeno, se observó que el metabolismo de la comunidad bentónica se reduce al decrecer las concentraciones de oxígeno.

Las pendientes de las curvas de regresión, que relacionan las tasas de decaimiento del oxígeno con las concentraciones de oxígeno, difieren significativamente entre los lagos estudiados. Estas pendientes estuvieron relacionadas con el contenido de materia orgánica total del sedimento (pendiente $=-3.79+0.42 \cdot \mathrm{MO}$, $\mathrm{r}^{2}=0.78, \mathrm{p}<0.05$ ), con el potencial redox (pendiente $\left.=3.83-0.01 \cdot \mathrm{Eh}, \mathrm{r}^{2}=0.88, \mathrm{p}<0.05\right)$, con el fósforo total de las aguas de fondo (pendiente $\left.=1.95+0.10 \cdot \mathrm{P}, \mathrm{r}^{2}=0.73, \mathrm{p}<0.05\right), \mathrm{y}$ con el nitrógeno total de las aguas de fondo (pendien$\left.\mathrm{te}=1.20+6.51 \cdot \mathrm{N}, \mathrm{r}^{2}=0.73, \mathrm{p}<0.05\right)$.

\section{Fauna ictica}

El nivel de nutrientes en los lagos no solo influye en la producción íctica, sino también en la 
Tabla 8. Especies de peces registradas en los 4 sistemas estudiados. Fish species registered for the 4 studied systems.

\begin{tabular}{|c|c|c|c|c|c|}
\hline Especies & & Lleulleu & Chica & Lanalhue & Grande \\
\hline \multirow[t]{6}{*}{ Nativas } & Percilia irwini & & $\checkmark$ & & $\checkmark$ \\
\hline & Galaxias maculatus & & $\checkmark$ & $\checkmark$ & $\checkmark$ \\
\hline & Cheirodon galusdae & & $\checkmark$ & & $\checkmark$ \\
\hline & Nematogenis inermis & & $\checkmark$ & & $\checkmark$ \\
\hline & Percichthys trucha & & & $\checkmark$ & $\checkmark$ \\
\hline & Geotria australis & & & & $\checkmark$ \\
\hline \multirow[t]{9}{*}{ Introducidas } & Oncorhynchus mykiss & & $\checkmark$ & & $\checkmark$ \\
\hline & Salmo trutta & $\checkmark$ & & & \\
\hline & Odontesthes bonariensis & $\checkmark$ & $\checkmark$ & $\checkmark$ & $\checkmark$ \\
\hline & Cyprinus carpio & $\checkmark$ & $\checkmark$ & $\checkmark$ & $\checkmark$ \\
\hline & Gambusia holbrooki & & $\checkmark$ & & $\checkmark$ \\
\hline & Cichlasoma facetum & & $\checkmark$ & & $\checkmark$ \\
\hline & Carassius carassius & & & & $\checkmark$ \\
\hline & Total Nativas / introducidas & $0 / 3$ & $4 / 5$ & $2 / 2$ & $6 / 6$ \\
\hline & Total & 3 & 9 & 3 & 12 \\
\hline
\end{tabular}

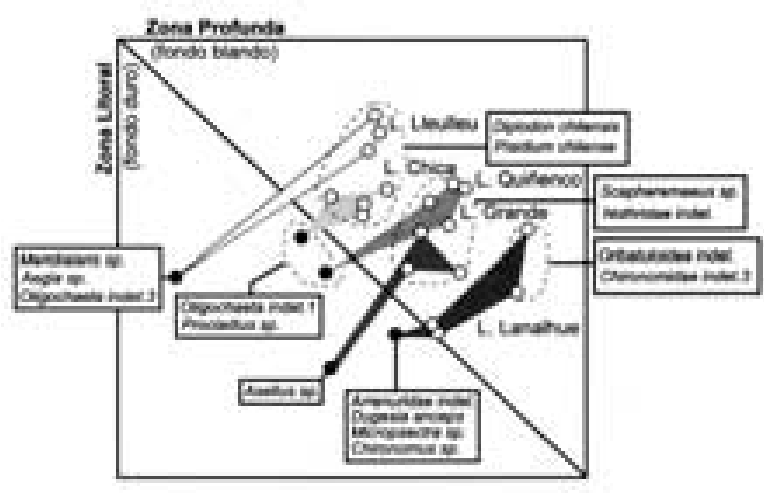

Figura 13. Especies indicadoras del bentos de la condición trófica de los lagos para ambientes litorales y profundos. Benthos trophic condition index species of the lakes, for littoral and deep environements

composición específica de la comunidad (Colby et al., 1972). En los sistemas estudiados la riqueza de especies varía de 3 en Lleulleu a 12 especies en Laguna Grande (Tabla 8), reflejando una tendencia al incremento en la riqueza y diversidad de especies en este ambiente de mayor trofía (Scasso, 1996). En los cuatro lagos, la relación de especies nativas a introducidas es cercana a 1:1, a excepción del lago Lleulleu (Corfo, 1995), donde, debido al uso de un único arte de pesca, no ha sido registrada la presencia de especies en la zona litoral. En la zona pelágica, Odontesthes bonariensis corresponde a la especie más abundante de los cuatro sistemas, seguida por Oncorhynchus mykiss en Laguna Chica y Cyprinus carpio en Lanalhue y Laguna Grande. La alta abundancia de O. bonariensis y $C$. carpio es común en sistemas eutróficos, donde son especies exitosas gracias a sus hábitos alimentarios oportunistas (Prochelle \& Campos, 1985; Vila \& Soto, 1984).

Por su parte, las especies de salmónidos responden inicialmente a la eutrofización con un aumento en su tasa de crecimiento corporal, pero luego disminuyen su reproducción, siendo finalmente reemplazadas por otras especies (Colby et al., 1972). Ello se refleja en la ausencia de $S$. trutta en los lagos Lanalhue, Grande y Chica, en tanto que habita en Lleulleu, al igual que en otros tres lagos oligotróficos de la región (Laja, Icalma y Galletué; Campos et al., 1993, Scasso \& Campos, 1998). La segunda especie salmonídea presente en estos sistemas, O. mykiss, parece adaptarse mejor que $S$. trutta a mayores niveles de eutroficación, ya que se encuentra presente en las lagunas Chica y Grande. Sin embargo, su aporte porcentual a la biomasa de la comunidad pelágica disminuye de un $26 \%$ en Laguna Chica a un $19 \%$ en Laguna Grande (Scasso, 1996). Su mejor adaptación a niveles intermedios de eutroficación quedan demostrados además en la 
mayor abundancia, biomasa y producción que alcanza en laguna Chica respecto de laguna Grande (Scasso \& Campos, 1998), (Tabla 9). De igual forma, $O$. bonariensis también refleja una mayor adaptación a ambientes mesotróficos, alcanzando mayor biomasa y producción en Laguna Chica y obteniendo un largo asintótico y edades significativamente mayores en Laguna Chica (longitud total máxima observada $53 \mathrm{~cm}$ y VIII años) que en Laguna Grande (43 $\mathrm{cm}$ y V años) (Scasso \& Campos, 1999). Sin embargo, la mayor tasa de crecimiento de O. bonariensis se produce en Laguna Grande, lo que se relacionaría con una mayor disponibilidad de alimento (Scasso \& Campos, 1999).

A pesar del mayor nivel de trófía de Laguna Grande, los valores de densidad íctica (1171 peces $\left.\mathrm{ha}^{-1}\right)$ y biomasa íctica $\left(563 \pm 177 \mathrm{~kg} \mathrm{ha}^{-1}\right)$ no presentan diferencias significativas con los obtenidos en Laguna Chica (896 peces ha-1 y $591 \pm 86 \mathrm{~kg} \mathrm{ha}^{-1}$ ). Sin embargo, ambos valores son significativamente mayores a los del Lago Icalma, oligotrófico (184 peces ha ${ }^{-1}$ y $164 \pm 24$ $\mathrm{kg} \mathrm{ha}^{-1}$; Scasso, 1996). De igual forma, la producción íctica y el máximo rendimiento sostenido no son significativamente diferentes en ambos sistemas, aún cuando, Laguna Grande permite la extracción de mayores cuotas de captura por especie (Tabla 9).

\section{DISCUSIÓN Y CONCLUSIONES}

Los ecosistemas acuáticos continentales interactúan con el sistema terrestre de diferentes maneras, así, la mantención de los procesos ecológicos son muy dependientes de esta relación (Tundisi et al., 1997), las que también dependen de las características geomorfológicas que han dado origen a las cuencas lacustres. Por lo tanto, es importante analizar estas interacciones en un contexto regional, histórico y a una escala geológica y actual. La evolución física y biológica de un lago es el resultado de un proceso dinámico el cual a su vez es dependiente de un sistema geomórfico (Tundisi et al., 1997). Así, las relaciones entre superficie terrestre, la hidrología de pendientes, la superficie del cuerpo de agua y el desarrollo de la línea de costa, entre otras, son fundamentales para entender la magnitud y carácter de las entradas de material alóctono a los lagos y en la formación de los patrones estacionales de estratificación física, química y biológica. Pero también es relevante tener presente la acción humana en una escala temporal apropiada a dicha acción, la que puede incidir fuertemente en el establecimiento de nuevos patrones geomorfológicos y también en las interacciones entre los sistemas terrestres y acuáticos.

El sistema estudiado ofrece una oportunidad para comprender las características ecológicas

Tabla 9. Producción íctica, máximo rendimiento sostenido y cuotas de captura por especie en Laguna Grande y Chica (Basado en Scasso 1996). Ichthyc production

\begin{tabular}{|c|c|c|c|c|c|c|}
\hline \multirow[b]{2}{*}{ Especie } & \multicolumn{3}{|c|}{ Laguna Chica de San Pedro } & \multicolumn{3}{|c|}{ Laguna Grande de San Pedro } \\
\hline & $\begin{array}{l}\text { Producción } \\
\quad \text { íctica } \\
\left(\mathrm{kg} \mathrm{ha}^{-1} \mathrm{anno}^{-1}\right)\end{array}$ & $\begin{array}{l}\text { Máximo } \\
\text { Rendimiento } \\
\text { Sostenido } \\
\left(\mathrm{kg} \mathrm{ha}^{-1} \mathrm{año}^{-1}\right)\end{array}$ & $\begin{array}{c}\text { Cuota de } \\
\text { captura } \\
\text { (peces/día) }\end{array}$ & $\begin{array}{c}\text { Producción } \\
\text { íctica } \\
\left(\mathrm{kg} \mathrm{ha}^{-1} \mathrm{año}^{-1}\right)\end{array}$ & $\begin{array}{c}\text { Máximo } \\
\text { Rendimiento } \\
\text { Sostenido } \\
\left(\mathrm{kg} \mathrm{ha}^{-1} \text { año }^{-1}\right)\end{array}$ & $\begin{array}{c}\text { Cuota } \\
\text { de captura } \\
\text { (peces/día) }\end{array}$ \\
\hline O. mykiss & 94 & 33.7 & 32 & 63 & 21.7 & 50 \\
\hline O.bonariensis & 269 & 123.5 & 36 & 159 & 114.3 & 96 \\
\hline P. trucha & - & - & - & 33 & 12.5 & 45 \\
\hline C.carpio & - & - & - & 65 & 21.5 & $\mathrm{~s} / \mathrm{r}$ \\
\hline TOTAL & 384 & 157 & 68 & 364 & 170 & 191 \\
\hline
\end{tabular}

$\mathrm{s} / \mathrm{r}$ : sin restricción 
presentes considerando que estas son las consecuencias de las interacciones en el tiempo que se han dado con los ecosistemas terrestres. Esto es posible por: a) la información limnológica base disponible y generada, b) el conocimiento que se ha logrado últimamente sobre los sistemas terrestres y c) por la evaluación de la magnitud de las actividades humanas efectuadas en ambos sistemas. De lo anterior resulta importante definir un marco de referencia respecto a los puntos indicados lo cual facilitará el entendimiento de algunas relaciones causa-efecto postuladas.

1. El sistema de lagos nahuelbutanos comparten en gran medida importantes características naturales básicas relacionadas con la geología, climatología, geomorfología, hidrografía, cobertura vegetal pretérita y actual.

2. Al mismo tiempo, producto de las relaciones que emergen entre el sistema geomórfico y el cuerpo de agua, se generan particularidades de cada ecosistema acuático, determinadas por relaciones cuantitativas como por ejemplo, las relaciones entre las superficies de las áreas de drenaje y la de los cuerpos de aguas, el desarrollo de la línea de costa, tiempo de renovación de las aguas, que a su vez determinan algunas de las características limnológicas (estratificación térmica, concentración de nutrientes) y el grado de impacto de algunas acciones humanas (contaminación orgánica, concentración de coliformes, modificación de sustratos de fondo).

3. Las principales acciones humanas efectuadas en el sistema son:

- Remoción del bosque nativo en las áreas de drenaje y su reemplazo por actividad agrícola y/o en mayor parte por plantaciones forestales (Pinus radiata y Eucalyptus spp.).

- Establecimiento de asentamientos humanos, actividades turísticas y recreativas, y construcción de caminos civiles y forestales afectando la configuración de pendientes cerca de los lagos.

- Introducción de especies de peces (Cyprinus carpio, Carassiuss carassius, Odontesthes bonariensis, Oncorhynchus mykis).
- Introducción de especies de malezas acuáticas (e.g. Egeria densa).

A lo anterior se debe agregar que ninguno de los sistemas acuáticos y sus respectivas cuencas se encuentran sometidos a un régimen de protección especial y prácticamente todas sus superficies son de carácter productivo y de desarrollo indígena (áreas de los Lagos Lanalhue y Lleulleu), lo que explica el alto nivel de intervención ha que ha sido sometido el sistema.

Como se indicó en los resultados, durante gran parte del presente siglo, el área de emplazamiento del sistema de lagos nahuelbutanos, ha sufrido una de las más importante modificaciones medio ambientales generadas desde la llegada de los colonizadores españoles; el reemplazo del bosque nativo por plantaciones forestales de P. radiata y Eucalyptus spp. Este proceso es el factor mas importante que ha producido el paulatino incremento de la exportación de sedimentos y nutrientes (Cisternas et al., 1997, 1999, 2000). Esta situación también ha sido descrita para otras áreas de la Región (Oyarzun 1993, 1997). Por las características de la actividad forestal, los periodos de cosechas son negativos, especialmente si las plantaciones se localizan en pendientes altas. Según los mismos autores, mas que las plantaciones forestales por si mismas, aparentemente es negativa la localización adoptada, y más aún la aplicación de la tala rasa como método de cosecha. La historia "ambiental" propuesta para laguna Chica de San Pedro y aplicable a todos las cuencas de drenaje del sistema de lagos nahuelbutanos consiste en: i) fase de degradación antrópica del bosque nativo, caracterizado principalmente por tala y quemas, para realizar siembras; ii) fase de preparación del suelo para las primeras plantaciones forestales y finalmente, iii) fase de activo proceso de crecimiento urbano desarrollado con mayor intensidad en las cuencas cercanas a la conurbación de Concepción.

Todo lo anterior indica que durante los últimos 50 años las cuencas hidrográficas localizadas en el sector norte de la Cordillera de Nahuelbuta han sido modificadas entre un 50 a 
un $90 \%$ de sus superficies, lo que en el transcurso del tiempo ha significado modificación de los gradientes de pendientes, incremento y alteraciones en los patrones de sedimentación y aportes de nutrientes a los cuerpos acuáticos, situación que se mantiene hasta hoy día.

La circulación de materia orgánica de origen terrestre en los lagos produce una considerable producción de nutrientes inorgánicos y pasa a constituir la base de varias cadenas tróficas a partir del detritus. En el área de estudio se han estimado aportes de sedimentos entre $0.10 \mathrm{a} 1.16 \mathrm{tm}$ ha ${ }^{-1}$ por año-1 (Cisternas et al., 2000). Así una de las consecuencias primaria del corte de los bosques son los cambios en las tasas de sedimentación. Después de la remoción de la cubierta vegetal, los suelos pueden permanecer descubiertos por meses (5-6 meses hasta un año). Todo lo anterior explicaría los cambios en la composición química de los sedimentos indicados por Urrutia et al. (2000) y Valdovinos y Figueroa (2000). Por otra parte las modificaciones en la cobertura vegetal produce también alteración en la pendiente modificando los patrones de escorrentía y de erodabilidad afectando también la entrada de sedimentos y nutrientes afectando las características de los sustratos litorales para invertebrados.

Otro efecto de las plantaciones tanto de Pinus como de Eucalyptus es la homogenización del detritus vegetal, muy diferente al producido por coberturas vegetales nativas, lo que produce cambios en la composición iónica de las aguas (Tundisi et al., 1997).

La influencia humana ha sido mayor en los lagos Grande y Chica de San Pedro y en el Lago Lanalhue por las influencia de áreas urbanas de Concepción y Contulmo respectivamente. Lo anterior ha significado por algún tiempo la entrada de aguas lluvias y aguas servidas, la modificación de sus pendientes por la construcción de caminos y accesos públicos y una fuerte alteración de la línea de costa por infraestructura turística y recreativa. Es justamente en los dos primeros lagos donde se han introducido malezas acuáticas dominadas por Egeria densa, que hasta hoy cubren toda la zona litoral de los lagos. Otros efectos fueron sobre la calidad del agua, particu- larmente en aquellos parámetros relacionados con la calidad microbiológica, la transparencia, las concentraciones de nutrientes, la presencia de floraciones algales, y la presencia de indicadores algales y bentónicos de incremento de la trofía.

Si se comparan los resultados de la clasificación de la calidad de agua de los lagos, con variables de respuesta biológica a los procesos de eutroficación, tales como indicadores fitoplanctónicos (Parra et al., 1999), bentónicos (Valdovinos et al., 2000) y fauna íctica (Scaso y Campos, 1998; 1999), se observan claras diferencias, las cuales pueden ser atribuidas al estado trófico de estos cuerpos de aguas. En los lagos que presentan una menor concentración de nutrientes y mejor calidad de agua, e.g. Lago Lleulleu y la Laguna Chica de San Pedro, la abundancia fitoplanctónica es de moderada a baja $(<150000$ cél./L). Esta condición es congruente con algunas características de las comunidades bióticas que son indicadores de buena calidad de agua, típicas de lagos oligo- a mesotróficos, tales como la elevada relación Bacillariophyceae / Chlorophyceae (>8). Con respecto a las comunidades de macroinvertebrados bentónicos, se observa una gran abundancia de bivalvos suspensívoros tales como Diplodon chilensis (Bivalvia: Hyriidae), lo cual de igual forma sugiere condiciones de buena calidad de agua. Lo mismo ocurre con la presencia de Salmo trutta en el lago Lleulleu, especies salmonídea de altos requerimientos de calidad de agua.

Por el contrario, en los lagos que presentan una mayor trofía y calidad de agua inferior, tales como Laguna Grande de San Pedro y el Lago Lanalhue, la abundancia fitoplanctónica es elevada (>400 000 cél./L) y la comunidad posee indicadores de moderada a mala calidad de agua, típicos de lagos meso- eutróficos tales como la baja proporción Bacillariophyceae / Chlorophyceae $(<8)$, y la presencia de Microcystis aeruginosa y $M$. wesembergii y desarrollo de floraciones algales. En relación a las comunidades de macroinvertebrados bentónicos, se observa la presencia de bioindicadores de regular calidad de agua tales como isópodos del género Asellus y ácaros Oribatuloidea que también son 
bioindicadores de moderada a mala calidad de agua. En los peces, son abundantes especies generalistas y tolerantes tales como Cyprinus carpio y Carassius carassius.

El análisis comparativo de los parámetros asociados a la comunidad fitoplanctónica de los cinco lagos, demostró que cada uno de ellos presenta una comunidad particular, con diferencias notables entre ellos y por lo tanto, no existe un patrón que los asimile. En ninguno de los lagos estudiados en periodo del año 1997 se detectaron floraciones algales o abundancias relevantes de especies indicadoras de contaminación orgánica. Se postula, sobre la base de la composición específica, especies más frecuentes y más abundantes, así como la densidad total del fitoplancton, la siguiente clasificación trófica: oligotrofía para el lago Lleulleu, una mesotrofía a una ligera eutrofía para la laguna Chica de San Pedro, eutrofía para Laguna Grande y Lanalhue y una condición trófica particular, que correspondería a una distrofía producto del material particulado orgánico y probablemente una importante concentración de material húmico, para laguna Quiñenco.

Laguna Quiñenco posee una condición de moderada calidad de agua, sin embargo, a diferencia de las Laguna Grande de San Pedro y el Lago Lleulleu, posee una baja abundancia fitoplanctónica $(<80000$ cél./L), a pesar de poseer significativas concentraciones de nutrientes. Esto se debería a que el factor limitante de la comunidad fitoplanctónica sería la baja penetración de la luz, asociada fundamentalmente a la elevada carga de seston y al color, debido a la presencia de ácidos húmicos, por lo cual corresponde a un típico lago distrófico (Wetzel, 1983). Por el contrario, la comunidad de macroinvertebrados bentónicos está compuesta por taxa indicadores de regular a buena calidad de agua.

Lo anterior también se ajusta a los resultados obtenidos sobre la tasa de consumo de oxígeno de los sedimentos (Valdovinos \& Figueroa, 2000). Este parámetro se utiliza como una medida integradora de la actividad metabólica de las comunidades bentónicas. Considerando que la intensidad de los procesos metabólicos de la zona profundal de un lago es dependiente de la producción de materia orgánica en la zona pelágica, las tasas de consumo de oxígeno de los sedimentos reflejan la condición trófica de todo el lago (Newrkla y Gunatilaka, 1982). A mayor tasa de consumo de oxígeno, menor es su calidad de agua. Los lagos con bajos contenidos de nutrientes y buena calidad de agua, coinciden con los que poseen las tasas de consumo de oxígeno más bajas (Lleulleu y Chica de San Pedro). Por el contrario, el lago con una calidad inferior, posee una elevada tasa de consumo de oxígeno (Grande de San Pedro). Laguna Quiñenco posee una condición intermedia. No se cuenta con datos de consumo de oxígeno del Lago Lanalhue que puedan ser discutidos.

Los lagos pueden ser clasificados también como oligotróficos, mesotróficos o eutróficos, basados en sus concentraciones de nutrientes o en las tasas de producción de materia orgánica (Valdovinos \& Figueroa, 2000). En los lagos estudiados, asumiendo que las entradas alóctonas de materia orgánica no tienen tanta relevancia como la producida en el interior de los lagos, la producción de la zona pelágica se traduce en una significativa sedimentación de material alóctono. De esta forma, los nutrientes asociados a la materia orgánica, son removidos temporalmente de la columna de agua. Estos nutrientes estarán nuevamente disponibles para la producción primaria, como resultado de la actividad metabólica de la comunidad bentónica. Debido a que la densidad y composición de especies de la comunidad bentónica profundal es fuertemente dependiente de la cantidad de materia orgánica producida en la zona pelágica, su actividad metabólica está ligada a la productividad del lago (Hayes \& MacAuley, 1959; Rybak, 1969; Margrave, 1973; Newrkla \& Gunatilaka, 1982; Riise \& Roos, 1997).

En el estudio de Valdovinos y Figueroa (2000), las tasas de consumo de oxígeno más elevadas fueron medidas en los sedimentos de Quiñenco seguidas por Grande. Comparativamente, bajos valores fueron medidos en los sedimentos de Chica y Lleulleu. Los resultados también mostra- 
ron que exponiendo en laboratorio los sedimentos a diferentes niveles de oxígeno, se observó que el metabolismo de la comunidad bentónica se reduce al decrecer las concentraciones de oxígeno. Eso es explicable debido a que la falta de oxígeno favorece la descomposición anaeróbica de la materia orgánica e incrementa la cantidad de metabolitos, incrementando el déficit de oxígeno en los sedimentos (Rybak, 1969; Dechev et al., 1977; Newrkla \& Gunatilaka, 1982; Riise \& Roos 1997). La falta de oxígeno suficiente actúa disminuyendo las tasas de consumo bentónico de oxígeno, como fue demostrado en los cuatro lagos. Las altas pendientes en las curvas de regresión en Quiñenco y Grande.

Los métodos empleados en este estudio comparativo de las tasas de consumo de oxígeno son simplificados y no necesariamente duplican las condiciones ocurridas en condiciones naturales, sin embargo, a pesar de estas dificultades, estas herramientas serían útiles para la evaluación cuantitativa del compartimento bentónico de un lago, en relación a su nivel trófico. Los resultados obtenidos sugieren que los factores abióticos de la columna de agua y sedimentos, afectan la estructura comunitaria de los macroinvertebrados bentónicos. Las comunidades varían siguiendo un continuo a lo largo de un gradiente de nivel trófico, a lo largo del cual se observa una clara sucesión de especies. Los datos son consistentes con la hipótesis que señala que un incremento del nivel trófico de un lago, debido a un aumento de macronutrientes como $\mathrm{P}$ y $\mathrm{N}$, favorece la productividad fitoplanctónica generando un incremento del contenido de materia orgánica de los sedimentos, lo cual afecta la estructura comunitaria de los macroinvertebrados bentónicos.

En cuanto a la ictiofauna, la dispar información disponible hace difícil el reconocimiento de patrones ictiofaunísticos debidos a los diferentes niveles de trofía. A pesar de ello, la información existente muestra algunas tendencias, tales como el aumento en el número de especies en el sistema más eutrófico, correspondiente a laguna Grande. Según Scasso \& Campos (1999) este hecho se debe a la mayor adición y mejor adaptación de especies exóticas como $C$. carpio y $C$. carassius a las aguas eutróficas. Además, es posible que la mayor heterogeneidad ambiental de la zona litoral de Laguna Grande, dada por la abundancia de hidrófitas vasculares, favorezca la presencia de un mayor número de especies. A pesar de esta mayor riqueza específica, la información existente muestra la tendencia de Laguna Grande (eutrófica) a presentar una menor productividad que Laguna Chica (mesotrófica).

Esto resulta consistente con la tendencia de la productividad íctica de sistemas leníticos a aumentar con el nivel de trofía sólo hasta cierto límite, ya que los estados avanzados de eutroficación presentan efectos negativos sobre las poblaciones de peces (Campos, 1993). Al respecto, Scasso (1996) indica que la menor productividad de Laguna Grande puede ser explicada en parte por el déficit de oxígeno durante primavera y verano, lo cual implica que los peces sólo utilicen los primeros 9 metros de la columna de agua en dichas épocas. Al evitar las zonas profundas de baja oxigenación las poblaciones de peces ven reducido el espacio disponible (Scasso, 1996; Scasso \& Campos, 1999), lo que estaría frenando la productividad en este sistema.

De todo lo expuesto queda de manifiesto que el grado de trofía y de calidad del agua de este sistema lacustre se relacionan con indicadores biológicos expresados en las diversas comunidades existentes y estos a su vez con el nivel de intervención de las cuencas hidrográficas. Queda todavía por avanzar en el conocimiento de mayor detalle sobre estas relaciones, ya que ellas permitirían predecir con mayor precisión la incidencia de acciones humanas sobre la integridad de estos ecosistemas.

\section{AGRADECIMIENTOS}

Se agradece a Yely Ambiado, Mauricio Aguayo, Ricardo Faúndes por su valiosa ayuda para la preparación del material gráfico. Esta investigación fue financiada por el Proyecto FONDECYT 196-0600. 


\section{BIBLIOGRAFÍA}

AMERICAN PUBLIC HEALTH ASSOCIATION (APHA). 1980. Standard methods for the examination of water and waste-water, New York.

APPLEBY, P.G., V. J. JONES \& J. C. ELLISEVANS. 1995. Readiometric dating of lake sediments from Signy Island. Journal of Paleolimnology, $13: 179-191$.

BARRIENTOS, C. 1990. Estructura dinámica de la vegetación en la hoya hidrográfica de la Laguna Chica de San Pedro. Tesina de Diplomado en Análisis y Gestión del Ambiente. Centro EULAChile, Universidad de Concepción, 23 pp.

BELLAIR , P. \& CH. POMEROL. 1977. Elementos de Géologie. A. Collin.

BERTALANFFY, L. 1938. A quantitative theory of organic growth inquiries on growth laws. Human biology, 10(2): 181-213.

CAMPOS, H., W. STEFFEN, G. AGÜERO, O. PÁRRA. \& L. ZÚÑIGA, L. 1992. Limnology of lake Ranco (Chile). Limnológica, 22 (4): 337-353.

CAMPOS, H., V. H. RUIZ, J. F. GAVILÁN \& F. ALAY. 1993. Peces del Río Biobio. Serie Publicaciones de Divulgación EULA, 5

CAMPOS, H. 1993. Procesos de eutroficación en lagos del sur de Chile. Estimación de los efectos de la acuicultura intensiva. Seminario Internacional Acuicultura y Medio Ambiente Fundación Chile.

CIER-SERPLAC. 1976. Atlas Regional, VIII Región del Biobio. Chile.

CISTERNAS, M., A. ARANEDA, O. RETAMAL \& R. URRUTIA. 1997. Variaciones Históricas en las tasas de erosión-sedimentación de un cuerpo lacustre antropizado: Utilización de geocronología radioisotópica. Revista de Geografía Norte Grande, 24: 151-156.

CISTERNAS, M., P. DEBELS, P. MARTÍNEZ \& R. SANHUEZA. 1999a. Cambios Históricos en el Uso del Suelo de una Pequeña Cuenca Lacustre de Nahuelbuta. Revista Geográfica de Chile Terra Australis, 44: 141-153.

CISTERNAS, M., P. MARTÍNEZ, C. OYARZÚN. \& P. DEBELS. 1999b. Caracterización del proceso de reemplazo de vegetación nativa por plantaciones forestales en una cuenca lacustre de la Cordillera de Nahuelbuta, VIII Región, Chile. Revista Chilena de Historia Natural, 72: 661-676.

CISTERNAS, M., L. TORRES, R. URRUTIA, A.. ARANEDA \& O. PARRA.. 2000 Comparación ambiental mediante registros sedimentarios entre las condiciones prehispánicas y actuales de un sistema lacustre. Revista Chilena de Historia Natural, 73: 151-162.

CISTERNAS, M., A. ARANEDA, P. MARTINEZ \& S. PEREZ. 2001. Effects of historical land use on sediment yield from a lacustrine watershed in central Chile. Earth Surface Processes and Landforms, 26(1): 63-76.

COLBY, P., G. R. SPANGLER, D. A. HURLEY \& A. M. MCCOMBIE. 1972. Effects of eutrophication on salmonid communities in oligotrophic lakes. $J$. Fish. Res. Bd. Can., 29: 975-983.

CORFO. 1995. Potencialidad de las aguas interiores en la zona sur de la Provincia de Arauco (comunas de Cañete a Tirúa): Lagos Lanalhue y Lleulleu. Fondos Estudios e Investigaciones CORFO.

DECHEV, G., S. YORDANOV \& E. MATVEEVA. 1977. Oxygen consumption and oxygen debt in bottom sediments. Arch. Hydrobiol. Suppl. 52: 63-71.

DELLAROSSA, V. \& O. PARRA. 1985. Estado Ambiental de la laguna Grande de San Pedro y del lago Lanalhue. Red Mínima de Control de Lagos. Convenio Dirección General de Aguas y Universidad de Concepción, Chile. Informe Final, $209 \mathrm{pp}$.

DEVYNCK, J. L. 1970. Contribución al estudio de la circulación atmosférica en Chile y clima de la región del Biobio. Universidad de Concepción, Depto. Geofísica, 174 pp.

DI CASTRI, F. 1968. Esbozo ecológico de Chile. In Biologie de L'Amerique australe. Deboutteville. C \& E. Rapoport (Eds.). Centre National de la Recherche Scientifique, $34 \mathrm{pp}$.

DOWNING, J. A., C. PLANTE \& S. LALONDE. 1990 Fish production correlated with primary productivity, not the morphoedaphic index. Can. J. Fish. Aquat. Sci., 47: 1929-1936.

DOWNING, J. A. \& C. PLANTE. 1993 Production of fish populations in lakes. Can. J. Fish. Aquat. Sci., 50: 110-120.

EDWARDS, R. W. \& H. L. J. ROLLEY. 1965. Oxygen consumption of river muds. J. Ecol., 53: $1-19$.

ENDLICHER, W. \& W. MACHEL. 1985. Natoural Resources, land use and degradation in the coastal zone of Arauco and Nahuelbuta Range. Geojournal, 11 (1):43-64.

FERRARIS, F. 1981. Hoja Los Angeles-Angol, Región del Biobio, 1: 250.000. Mapa Geológico Preliminar $N^{\circ} 5,10 \mathrm{pp}$, Sernageomin, Santiago. 
FERRARIS, F. \& R. BONILLA. 1981. Hoja AraucoLebu, Región del Biobio, 1: 250.000. Mapa Geológico Preliminar $N^{\circ} 6,26 \mathrm{pp}$, Sernageomin, Santiago.

FUENZALIDA, H. 1971. Climatología de Chile. Publicación Int. Fac. de Ciencias Físicas y Matemáticas, Universidad de Chile, 73 pp.

HARGRAVE, B. T. 1973. Coupling carbon flow through some pelagic and benthic communities. $J$. Fish. Res. Bd Canada, 30: 1317-1326.

HARGRAVE, B. T. 1976. Metabolism at the benthic boundary. In: The benthic boundary layer. I. N. McCave (ed.). Plenum Press. 232 pp.

HAYES, F. . \& M. A. McAULEY, M.A. 1959. Lake water and sediment V. Oxygen consumed in water over sediment cores. Limnol. Oceanogr., 4: 291-298.

HUTCHINSON, G. E. 1957. A treatise on Limnology, Vol. 1. John Wiley, New York.

KATZ, H. R . 1970. Randpazifische Bruchtektonik am Beipiel Chiles und Neuseelands. Geologische Rundschau, 59: 898-926.

LARSEN, R. J., C. G. SANDERSON \& J. KADA. 1995. EML Surface Air Sampling Program. Data Report. ONU, 248 pp.

LEWIS, D.W. 1984. Practical Sedimentology. Hutchinson Ross Publishing company. Strowdsburg, Pennsylvania. 229 pp.

MARDONES, M. \& E. JAQUE. 1996. Geomorfología del valle del río Laja. I Taller Internacional de geoecología de Montaña y desarrollo Sustentable de los Andes del Sur. The United Nations University: 271-286.

MARDONES, M. \& C. D. REUTHER. 1999. Geomorphological aspects of the drainage pattern arround lake Lanalhue and lake Lleulleu in the actice convergent margin setting of South-Central Chile. Mitteilungen Geologische und Paläontologisches Institut und Museum, Universität Hamburg, 83: 75-88.

MILLS, A. 1978. A comparison of methods of determining carbon in marine sediments from de National Status and Trends Program. NOAA Technical Memorandum NOS OMA 59: 112 pp.

MOSSETTI, F. 1977. Le acqua. Colección II Nostro Universo. UTET.

NEWRKLA, P. \& A. GUNATILAKA. 1982. Benthic community metabolism of three Austrian pre-alpine lakes of different trophic conditions and its oxygen dependency. Hydrobiologia, 92: 531-536.

NYGAARD, G. 1949. Hydrobiological studies in some ponds and lakes. II. The quotient hypothesis and some new or little known phytoplankton organisms. Biol. Skr., 7: 1-293.

OYARZUN, C. E. 1993. Evaluación del modelo U.S.L.E. para predecir pérdidas de suelo en áreas forestadas de la cuenca del río Bio-Bio. Bosque, 14(1): 45-54.

OYARZUN, C. E. 1995. Land use, hydrological properties, and soil erodibilities in the Bio-Bio river basin, Central Chile. Mountain Research and Development, 5(4): 331-338.

PAMATMAT, M. M. \& K. BANSE. 1969. Oxygen consumption by the seabed - II. In situ measurements to a depth of $180 \mathrm{~m}$. Limnol. Ocenogr., 14: 250-259.

PARRA O. 1989. La eutroficación de la Laguna Grande de San Pedro: Un caso de estudio. Ambiente y Desarrollo, 5(1): 117-136.

PARRA, O., V. DELLAROSSA \& E. UGARTE. 1976. Estudio limnológico de las lagunas "Chica de San Pedro", La Posada" y "Lo Méndez" I. Análisis cuali y cuantitativo del plancton invernal. Bol. Soc. Biol. Concepción, 50: 73-86.

PARRA, O., E. UGARTE, E. BALABANOFF, S. MORA, M. LIEBERMANN \& A. ARON. 1980. Remarks on a bloom of Microcystis aeruginosa Kuetzing. Nova Hedwigia, 33: 971-1004.

PARRA, O., E. UGARTE \& V. DELAROSSA. 1981. Periodicidad estacional y asociaciones en el fitoplancton de tres cuerpos lénticos de la Región de Concepción, Chile. Gayana Botánica, 36 :1-35.

PARRA, O., M. GONZALEZ, V. DELLAROSSA, P. RIVERA. \& M. ORELLANA. 1982-1983. Manual taxonómico del fitoplancton de aguas continentales de Chile. Vol. I, 70 pp; Vol. II, 82 pp.; Vol. III, 99 pp. Vol. V 353 pp.

PARRA, O., C. JARA \& L. GUZMÁN. 1989. Las lagunas intraurbanas de Concepción: Estado actual y perspectivas de recuperación y uso. Actas del III Encuentro Nacional del Medio Ambiente, 301-313.

PARRA, O., H. CAMPOS, W. STEFFENS, G. AGÜERO, S. BASUALTO, D. AVILES \& M. VIGHI. 1993. Estudios limnológicos de los lagos Icalma y Galletué: Lagos de origen del río Biobio (Chile Central). Monografía Científicas EULA, Ed. Universidad de Concepción, Chile. 12: 161-188.

PARRA, O., C. VALDOVINOS \& A. FIGUEROA. 1998. Caracterización física y química de 5 lagos de Chile Central. Gayana, (in press).

PARRA O., S. BASUALTO, R. URRUTIA \& C. VALDOVINOS. 1999. Estudio comparativo de la 
diversidad fitoplanctónica de cinco lagos de diferentes niveles tróficos. Gayana. 56(2) :25-40.

PIÑONES, O. \& I. TOMICIC. 1995. Estudio de los niveles radiológicos-ambientales en Chile durante el periodo 1966-1994. Nucleotécnica, 29:67-82.

PROCHELLE, O. \& H. CAMPOS. 1985. The biology of the introduced carp Cyprinus carpio L., in the river Cayumapu, Valdivia, Chile. Studies on Neotropical Fauna and Environment., 20(29): 65-82.

RICKER, W.E. 1981. Computation and interpretation of biological statistics of fish populations. Bull. Fish. Res. Bd. Canada:191-382.

RIISE, J. C. \& N. ROOS. 1997. Benthic metabolism and the effects of bioturbation in a fertilised polyculture fish pond in Northeast Thailand. Aquaculture, 150(1-2): 45-62.

RIVERA, P., O. PARRA, M. GONZÁLEZ, V. DEALLAROSSA \& M. ORELLANA. 1983. Manual Taxonómico del Fitoplancton de Aguas Continentales. Editorial Universidad de Concepción, Vol. IV, Bacillariophyceae. 97 pp.

ROSENBERG, D. M. \& V. H. RESH. 1993. Freshwater biomonitoring and benthic macroinvertebrates. Chapmann \& Hall.

RYBAK, J. I. 1969. Bottom sediments of lakes of various trophic type. Ecol. Pol., 17: 611-662.

RYDING, S. \& W. RAST. 1992. El control y de la eutrofización en lagos y pantanos. UNESCO, Ed. Pirámide, Madrid.

SCASSO, F. 1996. Productividad íctica en lagos de diferente estado trófico: recomendaciones de conservación para pesca deportiva. Tesis de Grado Centro EULA-Chile Universidad de Concepción.

SCASSO, F. \& H. CAMPOS. 1998. Oncorhynchus mykiss (Pisces, Salmonidae) populations in lakes of different trophic levels of the Biobío river basin, Chile. Verh. Internat. Verein. Limnol., 26: 2320-2323.

SCASSO, F. \& H. CAMPOS. 1999. Comparison of two populations of silverside (Odontesthes bonariensis) in Eutrophic lakes of Central Chile. Journal of Freshwater Ecology, 14(1): 61-70.

SMITH, K. L. 1973. Respiration of a sublittoral community. Ecology, 54: 1065-1075.

STRICKLAND, J. D. H. \& PARSONS, T. R. 1978. A practical handbook of seawater analysis. Bull. Fish. Res. Bd Canada, 167.
TUNDISI, J. G., Y. SAIJO \& T. SUNAGA. 1997. Ecological effects of Human Activities in the Middle Rio Doce Lakes. In: Limnological Studies on the Rio Doce Valley Lakes, Brazil. J. G. Tundisi \& Y. Saigo (eds.).

URRUTIA, R., K. SABBE, F. CRUCES, K. POZO, J. BECERRA, A. ARANEDA, W. VYVERMAN \& O. PARRA. Paleolimnological studies of Laguna Chica of San Pedro (VIII Region): Diatom, hydrocarbons and fatty acid records. Revista Chilena de Historia Natural, 73:593-604. 2000.

URRUTIA, R., M. CISTERNAS, A. ARANEDA, O. RETAMAL, O. PARRA \& M. MARDONES. 2000. Caracterización morfométrica y sedimentológica de cinco lagos costeros de la VIII Región, Chile. Revista Geográfica de Chile Terra Australis, 45:7-24.

UTERMOHL, H. 1957. Zur Vervollkommung der quantitativen Phytoplankton Methodik. Mitt. Int. Vereinigung Theor. Angew. Limnol., 15: 158-163.

VALDOVINOS, C. \& A. R. FIGUERO. 2000. Benthic community metabolism and trophic conditions of four South American lakes. Hydrobiologia, 429: 151-156.

VALDOVINOS. C., O. PARRA, R. FIGUEROA, R. URRUTIA \& M. CISTERNAS. 2000. Clasificación de la Calidad de las Aguas de Cinco Sistemas Lacustres de Chile Central sometidos a distintos niveles de intervención Humana (enviada).

VEYL, C., 1961. Contribución al conocimiento de la Geología regional de la provincia de Concepción. Inst. de Química. Geología. Universidad de Concepción. Publicación interna.

VILA, I. \& D. SOTO. 1984. Odontesthes bonariensis "pejerrey argentino", una especie para cultivo extensivo. FAO Documento técnico, 4: 224 228.

VOLLENWEIDER, R. A. 1968. Scientifical fundamentals of the eutrophication of lakes and flowing waters, with particular reference to nitrogen and phosphorus as factors in eutrophication. Rep. Organis. Econ. Coop. And Dev., DAS/CSI/68.27. Paris.

WENTWORTH, C. K. 1922. A scale of grade and class terms for clastic sediments. J. Geol., 30:377392. 